\title{
Removal of Colored Organic Pollutants from Wastewaters by Magnetite/Carbon Nanocomposites: Single and Binary Systems
}

\author{
Simona Gabriela Muntean (DD, ${ }^{1}$ Maria Andreea Nistor, ${ }^{1}$ Eliza Muntean (D), \\ Anamaria Todea, ${ }^{2}$ Robert Ianoş, ${ }^{2}$ and Cornelia Păcurariu ${ }^{2}$ \\ ${ }^{1}$ Institute of Chemistry Timişoara of Romanian Academy, 24 Mihai Viteazul Str., 300223 Timişoara, Romania \\ ${ }^{2}$ Faculty of Industrial Chemistry and Environmental Engineering, Politehnica University of Timişoara, 6 Pîrvan Blv., \\ 300223 Timişoara, Romania \\ Correspondence should be addressed to Simona Gabriela Muntean; sgmuntean@yahoo.com \\ and Eliza Muntean; eliza.muntean@yahoo.ro
}

Received 13 January 2018; Accepted 19 March 2018; Published 20 May 2018

Academic Editor: Alina Barbulescu

Copyright (C) 2018 Simona Gabriela Muntean et al. This is an open access article distributed under the Creative Commons Attribution License, which permits unrestricted use, distribution, and reproduction in any medium, provided the original work is properly cited.

\begin{abstract}
This work develops a methodology for selective removal of industrial dyes from wastewaters using adsorption technology based on magnetic adsorbents. The magnetic nanoparticles embedded within a matrix of activated carbon were tested as adsorbents for removal of industrial dyes from aqueous solutions. The effects of four independent variables, solution $\mathrm{pH}$, initial concentration of pollutant, adsorbent dose, contact time, and their interactions on the adsorption capacity of the nanocomposite were investigated in order to optimize the process. The removal efficiency of pollutants depends on solution $\mathrm{pH}$ and increases with increasing the carbon content, with initial concentration of the pollutants, the temperature, and the dose of magnetite/carbon nanocomposites. Pseudo-second-order kinetic model was fitted to the kinetic data, and adsorption isotherm analysis and thermodynamics were used to elucidate the adsorption mechanism. The maximum adsorption capacities were $223.82 \mathrm{mg} \mathrm{g}^{-1}$ for Nylosan Blue, $114.68 \mathrm{mg} \mathrm{g}^{-1}$ for Chromazurol S, and $286.91 \mathrm{mg} \mathrm{g}^{-1}$ for Basic Red 2. The regeneration and reuse of the sorbent were evaluated in seven adsorption/desorption cycles. The optimum conditions obtained for individual adsorption were selected as starting conditions for simultaneous adsorption of dyes. In binary systems, in normal conditions, selectivity decreases in the order: Red Basic $2>$ Nylosan Blue > Chromazurol S.
\end{abstract}

\section{Introduction}

Progress of various industries from the past decade led to a drastic increase in industrial effluent discharge, causing dramatically environmental pollution as well as serious life-threatening problems for environment. With regard to organic pollutants, dyes possess a high capacity to modify the environment due to their strong color and visual pollution and also cause changes in biological cycles mainly affecting photosynthesis processes. More than 10,000 tons of dyes are used in different industries, and approximately 100 tons are released into water streams, annually. Their concentration in wastewaters usually varies from 10 to $200 \mathrm{mg} \mathrm{L}^{-1}$ [1].

Release of industrial effluent without proper and prior treatment into the environment is one of the major causes leading to a burden of healthcare issues worldwide. For water purification, there is a need for technologies that have the ability to remove toxic contaminants from the environment to a safe level and to do so rapidly, efficiently, and within a reasonable costs framework. Adsorption process provides an attractive alternative for the treatment of colored wastewaters due to its simplicity, selectivity, and efficiency [25].

In recent years, magnetic nanoparticles (NPs) have attracted much interest in many environmental engineering related applications. With reported sizes ranging from 1 to $100 \mathrm{~nm}$, high surface-to-volume ratio, and high loading capacity, NPs were successfully used as strong adsorptive materials for pollutants adsorption from contaminated water $[6,7]$. 
TABLE 1: Features of magnetite/carbon nanocomposites prepared by combustion synthesis [9].

\begin{tabular}{lccccc}
\hline Sample & $\begin{array}{c}\mathrm{Fe}_{3} \mathrm{O}_{4} / \mathrm{C} \\
\text { mass ratio }\end{array}$ & $\begin{array}{c}\mathrm{SSA} \\
\left(\mathrm{m}^{2} / \mathrm{g}\right)\end{array}$ & $\begin{array}{c}\text { ESA } \\
\left(\mathrm{m}^{2} / \mathrm{g}\right)\end{array}$ & $\begin{array}{c}\text { Micropore volume } \\
\left(\mathrm{cm}^{3} / \mathrm{g}\right)\end{array}$ & $\begin{array}{c}M_{S} \\
(\mathrm{emu} / \mathrm{g})\end{array}$ \\
\hline PM-1 & $1 / 0$ & 75 & 71.2 & 0.001 \\
PM-2 & $1 / 1$ & 360 & 148.4 & 0.096 \\
PM-3 & $1 / 2$ & 522 & 204.5 & 0.144 & 39.7 \\
PM-4 & $1 / 5$ & 706 & 245.5 & 0.212 & 21.9 \\
PM-5 & $1 / 10$ & 814 & 307.9 & 0.234 & 7.8 \\
PM-6 & $0 / 1$ & 890 & 321.1 & 0.264 & 0.4 \\
\hline
\end{tabular}

SSA: BET specific surface area, ESA: external surface area, and $M_{S}$ : specific saturation magnetization.

The key to adsorption technology lies in the effectiveness and efficiency of adsorbent. Although commercial activated carbon has been most widely applied in adsorption, its microporous nature has limited the pore utility and adsorption capacity for large molecules [8].

In this work, three industrial dyes have been selected as pollutants. As adsorbent in this work a combination of active carbon and magnetic nanocomposite synthesized by combustion method has been selected.

The adsorption processes were first in detail investigated for single component solutions in terms of $\mathrm{pH}$, initial concentration, adsorbent dose, contact time, and temperature effect, completed by kinetics, equilibrium, and thermodynamics studies.

Subsequently the adsorption studies were performed for six combinations of the selected dyes mixed as binary systems.

The obtained results were compared with the previously reported data on different adsorbents for the same dyes and the selected magnetite nanocomposite from this work demonstrates its superiority and the potential as a new efficient adsorbent for the removal of dyes in binary systems from aqueous solutions.

\section{Experimental}

2.1. Materials. The starting raw materials for nanocomposites synthesis were activated carbon (Utchim), iron nitrate nonahydrate $\left(\mathrm{Fe}\left(\mathrm{NO}_{3}\right)_{3} \cdot 9 \mathrm{H}_{2} \mathrm{O}\right.$, Roth), and tartaric acid $\left(\mathrm{C}_{4} \mathrm{H}_{6} \mathrm{O}_{6}\right.$, Merck).

Investigated dyes were supplied by Chemical Romania and Colorom Codlea. Chromazurol S (C.I. 43825, ChS) is used as indicator for metal titration, Nylosan Blue (Acid Blue 129, C.I. 62058, NB) is an antraquinonic dye mainly used for wool, silk, polyamide fiber, and leather dyeing but is a skin and eye irritant, and Safranin T (Basic Red 2, C.I. 50240, BR2) is a water soluble organic dye, used in textile industries. Safranin can cause eye burns which may be responsible for permanent injury to the cornea and conjunctiva in human and rabbit eyes. Contact with Safranin dye also causes skin and respiratory tract irritation [17]. The industrial applications of these dyes in different fields confirm the necessity for development of efficient adsorbents.

All reagents were used as received, without further purification. Working dye solutions were prepared with distilled water. The solution $\mathrm{pH}$ was adjusted to the desired values using $\mathrm{HCl}\left(0.1 \mathrm{~mol} \mathrm{~L}^{-1}\right)$ or $\mathrm{NaOH}\left(0.1 \mathrm{~mol} \mathrm{~L}^{-1}\right)$ solutions.

2.2. Preparation of Magnetite/Carbon Nanocomposites. Magnetite/carbon nanocomposites (MNC) having different $\mathrm{Fe}_{3} \mathrm{O}_{4} / \mathrm{C}$ mass ratios, ranging from $1 / 1$ to $1 / 10$ (Table 1 ), were prepared by solution combustion synthesis. The detailed procedure about the preparation route and sample characterization is presented in a previous paper [9]. Briefly, activated carbon impregnated with the precursor solution of iron nitrate nonahydrate $(0.09 \mathrm{~mol})$ and tartaric acid $(0.138 \mathrm{~mol})$ was heated to $400^{\circ} \mathrm{C}$ inside a flask, in the absence of air. In order to conduct the combustion reaction in the absence of air, the starting raw materials were placed inside a round bottom flask and heated to $400^{\circ} \mathrm{C}$, as described elsewhere. During heating, water evaporates and the air from the flask expands. Driven by the increasing pressure, this mixture of gases is bubbled in a Berzelius glass filled with water, so that the air partial pressure decreased. This way, the atmospheric oxygen is prevented from getting inside the flask during the combustion process. After water evaporation, a smouldering combustion reaction began, accompanied by the release of large amounts of gases. The reaction product was hand-ground, washed with distilled water, and dried [9].

2.3. Adsorption Experiments. The prepared magnetite/carbon nanocomposites were introduced in dye solutions in flat-bottom glass flasks, and adsorption experiments were performed in a thermostat shaker with a constant shaking speed of $180 \mathrm{rpm}$. The adsorbent synthesis and the adsorption process are schematically presented in Figure 1.

At previously defined time intervals, the sorbent was separated via an external magnetic field, and the samples were collected for dye concentration measurements. For the dye desorption, the dye-loaded MNC were dispersed in $50 \mathrm{~mL}$ of ethanol solution (anhydrous alcohol : water $=1: 1$ ) and shaken for $60 \mathrm{~min}$. After magnetic separation, the concentration of the released dye in the supernatant was spectrophotometrically determined by measuring dye absorbance at maximum wavelength, using a calibration curve (SuppFig. 1).

After desorption, the magnetic sorbent was washed for three times with distilled water, dried at $70^{\circ} \mathrm{C}$ for $1 \mathrm{~h}$, and reused for adsorption in the next cycle. To validate the reusability of the magnetic sorbent, seven cycles of consecutive adsorption-desorption were carried out at $25^{\circ} \mathrm{C}$. 




FIGURE 1: Route of synthesis of MNC and their application for dyes removal.

The optimum adsorption conditions were determined by studying several experimental variables, including $\mathrm{pH}$ value (2.6-14.0), sorbent dose $\left(0.25-3.0 \mathrm{~g} \mathrm{~L}^{-1}\right)$, dye initial concentration (10-250 $\left.\mathrm{mg} \mathrm{L}^{-1}\right)$, and temperature $\left(25,40\right.$, and $\left.60^{\circ} \mathrm{C}\right)$. The dyes concentration was measured using a $U V$-Vis JASCO $V$-730 spectrophotometer, by monitoring the absorbance changes at the wavelength of maximum absorbance: $465.7 \mathrm{~nm}$ (ChS), $629.5 \mathrm{~nm}(\mathrm{NB})$, and $516 \mathrm{~nm}$ (BR2).

Using these experimental values, the adsorption capacity (1) and the percentage of dye removal (2) were calculated.

$$
\begin{gathered}
q_{t}=\frac{\left(C_{0}-C_{t}\right) \cdot V}{W} \\
R=\frac{C_{0}-C_{e}}{C_{0}} \cdot 100,
\end{gathered}
$$

where $q_{t}$ represents the amount of dye adsorbed per unit of adsorbent ( $\left.\mathrm{mg} \mathrm{g}^{-1}\right), R$ is the percentage of dye removal (\%), $C_{0}, C_{t}$, and $C_{e}$ are the concentrations of the dye solution at initial time, at different periods of time, and at equilibrium $\left(\mathrm{mg} \mathrm{L}^{-1}\right), V$ is the volume of solution $(\mathrm{L})$, and $W$ is the mass of the sorbent $(\mathrm{g})$.

\section{Results and Discussion}

3.1. Characterization of Magnetite/Carbon Nanocomposites (MNC). Our goal was to obtain a new sorbent that combines good adsorption capacity given by activated carbon with good sorbent separation out of solution, given by magnetite. The structure and morphology of the MNC nanocomposites were investigated by X-ray diffraction (XRD), FTIR spectroscopy, scanning electron microscopy- (SEM-) energy dispersive $\mathrm{X}$-ray (EDX), thermal analysis, and $\mathrm{N}_{2}$ adsorptiondesorption technique. The sample characterization is presented in a previous paper [9].

By comparing the specific surface area of the magnetite $\left(75 \mathrm{~m}^{2} / \mathrm{g}\right)$ with that of the activated carbon $\left(890 \mathrm{~m}^{2} / \mathrm{g}\right)$ and that of the samples, it is clear that the high specific surface area of the composites is due to the presence of activated carbon in all the samples. As the mass ratio of activated carbon increases, the BET surfaces increased from $360 \mathrm{~m}^{2} / \mathrm{g}$ to $814 \mathrm{~m}^{2} / \mathrm{g}$ (Table 1 ) which is closed to activated carbon specific surface area. The average size of the crystallites of magnetite, calculated by the Sherrer equation, varied between 12 and $21 \mathrm{~nm}$. The thermal behavior and textural properties of the samples are significantly influenced by the carbon content.

The endothermic effect at about $100^{\circ} \mathrm{C}$ on the DSC curves (Figure 2), accompanied by weight loss on the TG curves, was attributed to the evaporation of the water present in the samples. The large exothermic effect between 400 and $800^{\circ} \mathrm{C}$, accompanied by a significant mass loss on the TG curve, is obvious in the overlap of two exothermic effects, due to combustion of both, fuel residues and carbon. The values of the saturation magnetization of the samples are in accordance with their phase composition, decreasing with the decrease of magnetite content, from 59.7 to $7.8 \mathrm{emu} / \mathrm{g}$. The MNC nanocomposites exhibited a ferrimagnetic behavior. All MNC samples exhibit similar isotherm shape that can be explained by the large amount of carbon content present in their composition (SuppFig. 2) [9].

3.2. Adsorption Studies. A promising adsorbent for largescale wastewater treatment must present a very good adsorption capacity, easy separation, and high stability. In this vein, the magnetite/carbon nanocomposites (MNC) were tested as adsorbents for removal of two anionic dyes, Chromazurol S (ChS) and Nylosan Blue (NB), and a cationic dye, Safranin T (Basic Red 2, BR2). Molecular structures of investigated dyes are presented in Figure 3.

3.2.1. Effect of $p H$. Solution $\mathrm{pH}$ is an important parameter of adsorption process which affects the adsorbent's surface charge as well as molecular stability of dyes (anionic or cationic molecule) [18]. The influence of $\mathrm{pH}$ was evaluated in the range of 2.6-14.0, using MNC sample PM-4, keeping all other variables constant. The results presented in Figure 4 indicate a direct dependence between the dyes removal yield and solution $\mathrm{pH}$.

The efficiency of anionic dyes (NB, ChS) removal was higher than $85 \%$ at $\mathrm{pH} 2.6$ and decreased when the $\mathrm{pH}$ increased to 13.2. This can be explained by the fact that the 

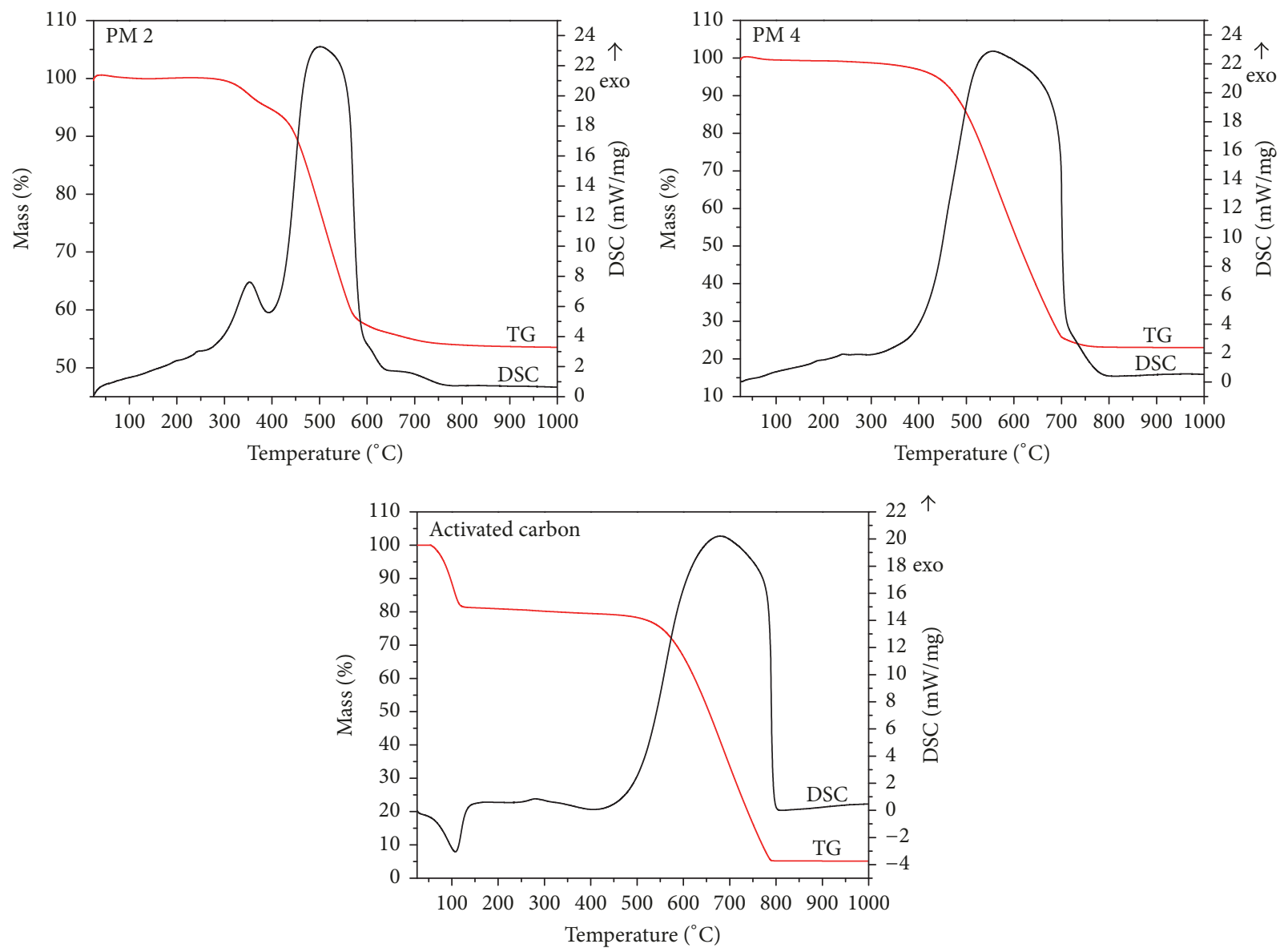

Figure 2: TG-DTA curves of samples PM-2, PM-4, and P-6 (activated carbon).<smiles>CC1=CC(=C(c2cc(C)c(O)c(C(N)=O)c2)c2c(Cl)ccc([N+]([O])=O)c2Cl)C=C(C(N)=O)C1=O</smiles><smiles></smiles><smiles>Cc1cc(C)c(Nc2cc([N+]([O-])O[Na])c(N)c3c2C(=O)c2ccccc2C3=O)c(C)c1</smiles>

Chromazurol S

FIGURE 3: Molecular structure of investigated dyes.

adsorption mechanism of anionic dyes at low $\mathrm{pH}$ value is controlled by electrostatic attractions between the positively charged surface of adsorbent, as a result of the protonation process, and the negatively charged dyes molecules. In the case of BR2, the removal percentage increased from $70.19 \%$ to $96.84 \%$ as the solution $\mathrm{pH}$ increases. At $\mathrm{pH}$ values higher than magnetite $\mathrm{pH}_{\mathrm{PZC}}$ (7.9) [19], the adsorption of cationic dye is enhanced due to electrostatic forces of attraction between the negatively charged surface of adsorbent and the positively charged dyes molecules. It is important to note the 


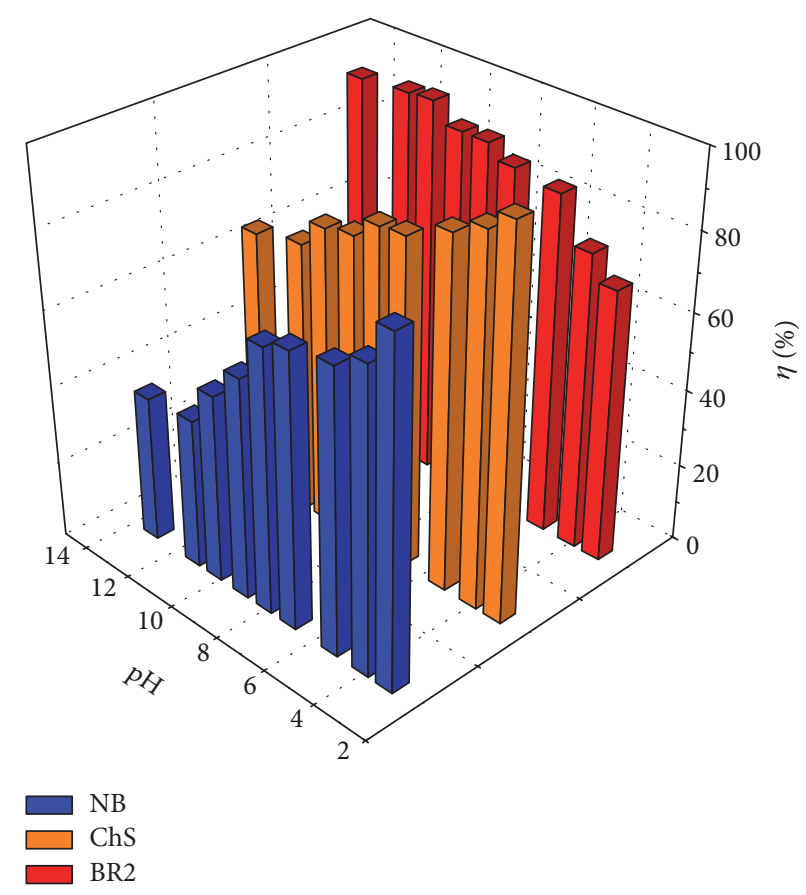

FIGURE 4: Effect of $\mathrm{pH}$ on dyes adsorption onto PM-4 adsorbent: contact time $120 \mathrm{~min}$, initial concentration $100 \mathrm{mg} \mathrm{L}^{-1}, 1 \mathrm{~g} \mathrm{~L}^{-1}$, and $25^{\circ} \mathrm{C}$.

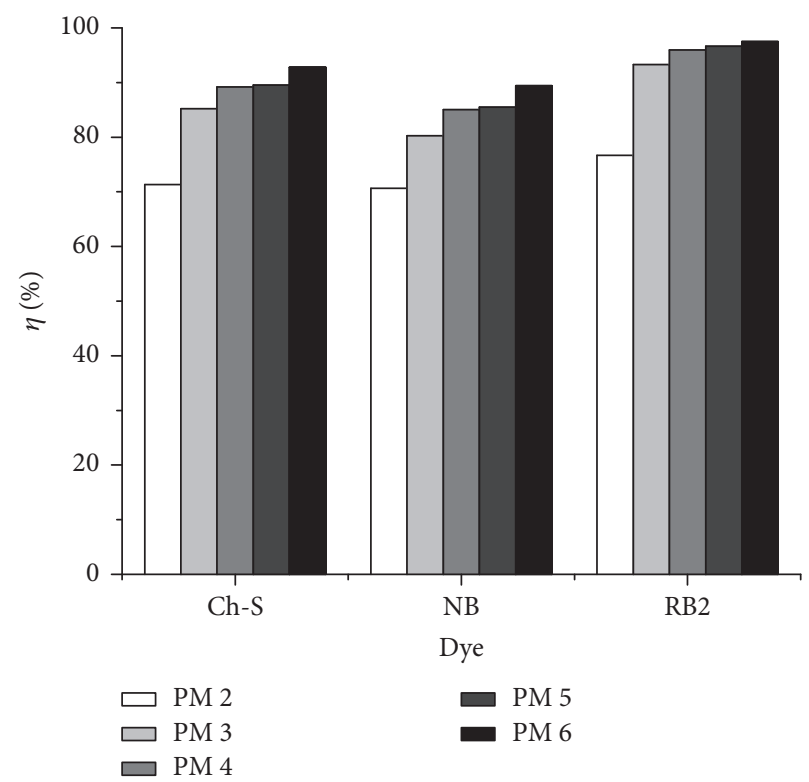

Figure 5: Influence of magnetite/carbon ratio on removal efficiency (dyes concentration $100 \mathrm{mg} \mathrm{L}^{-1}, 25^{\circ} \mathrm{C}, \mathrm{pH} 7.4$ for $\mathrm{NB}, 7.1$ for ChS, and 6.7 for BR2).

high removal efficiency even at neutral $\mathrm{pH}$ (67.89\% for NB, $82.95 \%$ for ChS, and $89.29 \%$ for BR2), which suggests another mechanism involving nonelectrostatic interactions between free electrons of the dye molecule present in aromatic ring and the delocalized $\pi$-electrons on the surface of adsorbent as previously mentioned by Istratie et al. [20]. Further experiments were carried out at the natural $\mathrm{pH}$ of each dye solution: 7.4 for $\mathrm{NB}, 7.1$ in case of $\mathrm{ChS}$, and 6.7 for BR2.
3.2.2. Effect of the Magnetite/Carbon Ratio on Removal Efficiency. The obtained results from the study of the effect of magnetite/carbon ratio on the removal efficiency are presented in Figure 5.

Sample 6 containing only activated carbon showed the best adsorption capacity. Activated carbon is a well-known and used sorbent for wastewater treatment, with high adsorption capacity [21, 22], but also with many disadvantages, 
TABLE 2: Effect of sorbent dose on dyes removal.

\begin{tabular}{lccc}
\hline $\begin{array}{l}\text { PM-4 dose } \\
\left(\mathrm{g} \mathrm{L}^{-1}\right)\end{array}$ & $\mathrm{NB}$ & $\begin{array}{c}R(\%) \\
\mathrm{ChS}\end{array}$ & $\mathrm{BR} 2$ \\
\hline 0.25 & 23.58 & 33.68 & 19.70 \\
0.5 & 48.66 & 40.30 & 39.94 \\
1 & 79.90 & 68.91 & 91.07 \\
2 & 85.97 & 79.63 & 95.98 \\
3 & 94.21 & 85.31 & 96.50 \\
\hline
\end{tabular}

such as high cost production, poor mechanical properties, and problems in separation, regeneration, and reuse [23-25]. This led to the search for new materials with an adsorption capacity close to that of activated carbon and with good regeneration and reuse. In this idea, we tested four samples which contain different magnetite/carbon ratio. As can be observed, the removal percentage increases from sample 2 to sample 5 due to the increase of the carbon content. The differences among the results obtained by using PM-4, PM5 , and P- 6 as adsorbent were in the range of $5 \%$ which demonstrates the high efficiency of investigated materials. In order to combine the good adsorption capacity (given by carbon) with the good separation and reutilization of the adsorbent (given by magnetite) the further studies were performed using PM-4.

3.2.3. Effect of Sorbent Dose. The influence of the sorbent dose towards the dye adsorption was studied at different quantities of PM-4 ranging from $0.25 \mathrm{~g} \mathrm{~L}^{-1}$ to $3 \mathrm{~g} \mathrm{~L}^{-1}$, at natural $\mathrm{pH}$ of dyes solutions, and at $25^{\circ} \mathrm{C}$, and results are presented in Table 2.

Removal efficiency of investigated dyes increases rapidly with an increasing amount from 0.25 to $1.0 \mathrm{~g} \mathrm{~L}^{-1}$ of PM4 nanocomposite. At the same time, further increasing the adsorbent dose from 1 to $3.0 \mathrm{~g} \mathrm{~L}^{-1}$ leads to only a small increase of the removal efficiency. This can be attributed to the availability of more adsorption sites as the adsorbent dose increased [26-28]. To get good removal efficiency, but still using as less sorbent, subsequent studies were conducted using $1 \mathrm{~g} \mathrm{~L}^{-1} \mathrm{PM}-4$ dose.

\subsubsection{Effect of Initial Dye Concentration and Contact Time.} We investigated the effect of the initial concentration of the dye adsorption process, in a wide range of concentrations between 10 and $250 \mathrm{mg} \mathrm{L}^{-1}$ at $25^{\circ} \mathrm{C}$ and natural $\mathrm{pH}$ values (7.4 for NB, 7.1 for ChS, and 6.7 for BR2). The concentration of the dye at $\lambda_{\max }$ was obtained using a standard calibration curve (SuppFig. 1).

As can be seen in Figure 6, the adsorption is very rapid in the initial stages of the adsorption, and it remained constant after reaching the equilibrium time. This can be explained by a large number of active centers at the beginning of adsorption and saturation of these centers on the surface of the adsorbent with achieving equilibrium. The necessary time for reaching the equilibrium increases with increasing the concentration due to the fact that adsorption involves film diffusion and internal diffusion [29]. The surface diffusion is rapid but the pore diffusion is slower, and the rate of diffusion in the internal adsorption sites decreased with increasing the initial dye concentration.

Very good results (higher than 95\%) for the dye removal percentage were obtained at low concentrations (Table 3), but even at high concentrations the removal percentage is high in case of BR2 (>93\%) and higher than $50 \%$ for NB and ChS dyes. The amount of dye adsorbed increased while the percentage removal decreased, with the increase in the initial dye concentration, which is in accordance with the literature data $[30,31]$.

3.2.5. Effect of Temperature. The effect of temperature on the sorption process was studied at three different temperatures (i.e., 25,40 , and $60^{\circ} \mathrm{C}$ ) at natural $\mathrm{pH}$ values (7.4 for $\mathrm{NB}, 7.1$ for ChS, and 6.7 for BR2). The amount of dyes adsorbed onto PM-4 as a function of contact time for different temperatures is presented in Table 3 .

A comparison of experimental data shows for all investigated dyes that the rise of temperature induced a positive effect on the removal percentage (Table 3 ). The adsorption capacity increases as the temperature increases [32], suggesting that dyes adsorption onto PM-4 is an endothermic process $[30,33]$. This can be explained by the fact that by increasing the temperature the dye aggregation is reduced and the diffusion of dye molecules into the pores of the absorber is facilitated $[34,35]$. On the other hand, there was a decrease of the necessary time for reaching the equilibrium as the temperature increases from $25^{\circ} \mathrm{C}$ to $60^{\circ} \mathrm{C}$. Within the first $40 \mathrm{~min}$, approximately $80 \%$ of the dyes are rapidly adsorbed. Later, the adsorption process slows as the system approaches equilibrium. The shorter the contact time in adsorption process, the lower the operational costs that recommend the adsorbent for large-scale industrial application.

These adsorption studies indicate that colored pollutants, such as NB, ChS, and BR2, can be easily removed from wastewaters by adsorption onto magnetite/carbon nanocomposites (SuppFig. 3). Due to their saturation magnetization, these adsorbents can be simply separable from the parent solution using a magnetic field, resulting in clean water.

3.3. Kinetics Studies. In the kinetic experiment, the changes of absorbance were determined at certain time intervals during the adsorption process. The experimental results obtained for the influence of initial concentration were analyzed using the pseudo-first-order Lagergren (3), pseudo-second-order (4), and intraparticle diffusion (5) models.

$$
\begin{aligned}
\ln \left(q_{e}-q_{t}\right) & =\ln q_{e}-k_{1} t \\
\frac{t}{q_{t}} & =\frac{1}{k_{2} q_{e}^{2}}+\frac{t}{q_{e}} \\
q_{t} & =k_{i} t^{0.5}+l,
\end{aligned}
$$

where $q_{e}$ and $q_{t}$ are the amount of solute adsorbed at equilibrium and at time $t$, respectively, per unit weight of adsorbent $\left(\mathrm{mg} \mathrm{g}^{-1}\right), k_{1}$ is Lagergren rate constant $\left(\mathrm{min}^{-1}\right), k_{2}$ 


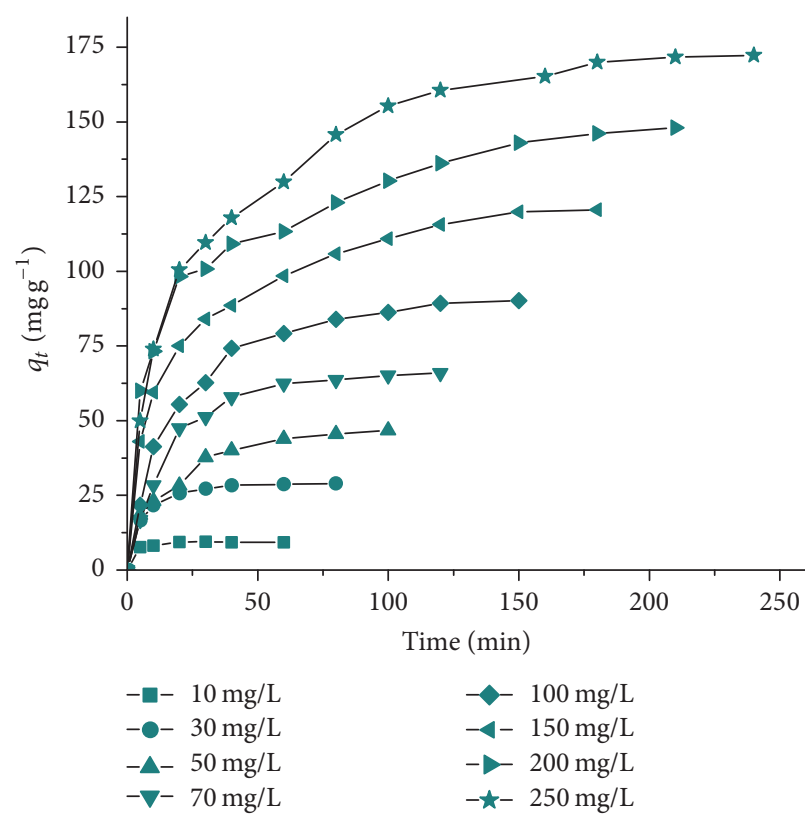

(a)

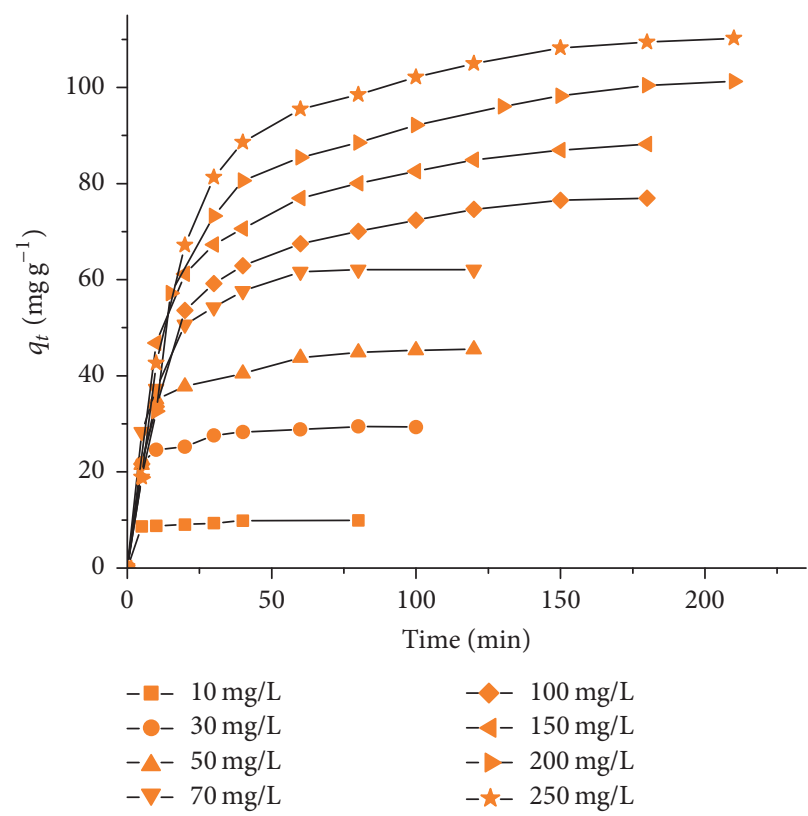

(b)



(c)

Figure 6: The effect of initial concentration on (a) NB, (b) ChS, and (c) BR2 dyes removal $\left(1 \mathrm{~g} \mathrm{~L}^{-1} \mathrm{PM}-4,25^{\circ} \mathrm{C}, \mathrm{pH} 7.4\right.$ for NB, 7.1 for $\mathrm{ChS}$, and 6.7 for BR2).

is the intraparticle diffusion rate constant $\left(\mathrm{g} \mathrm{mg}^{-1} \mathrm{~min}^{-1}\right)$, and $k_{i}$ is the intraparticle diffusion rate constant $\left(\mathrm{mg} \mathrm{g}^{-1} \mathrm{~min}^{-0.5}\right)$ and $l$ is the effect of boundary layer thickness.

The statistical criteria used to determine the best fitting kinetic model were the standard deviation (SD) and the squared multiple regression coefficient $\left(R^{2}\right)$. The comparison of experimental (obtained for the influence of temperature) and calculated adsorption capacities and the kinetic parameters estimated from (3), (4), and (5) are presented in Table 4.
The pseudo-second-order model was the best applicable kinetic model for the investigated dyes removal kinetics, emphasized by the accordance between the experimental and calculated $q_{e}$ values. With increasing the temperature, an increase of the pseudo-second-order rate constant $k_{2}$ was observed, pointing out that the necessary time for reaching the equilibrium decreased with increasing temperature. Similar results were obtained for the application of modified magnetic nanocomposites for dye removal $[28,36,37]$. 
TABLE 3: Influence of the process variables on the adsorption process.

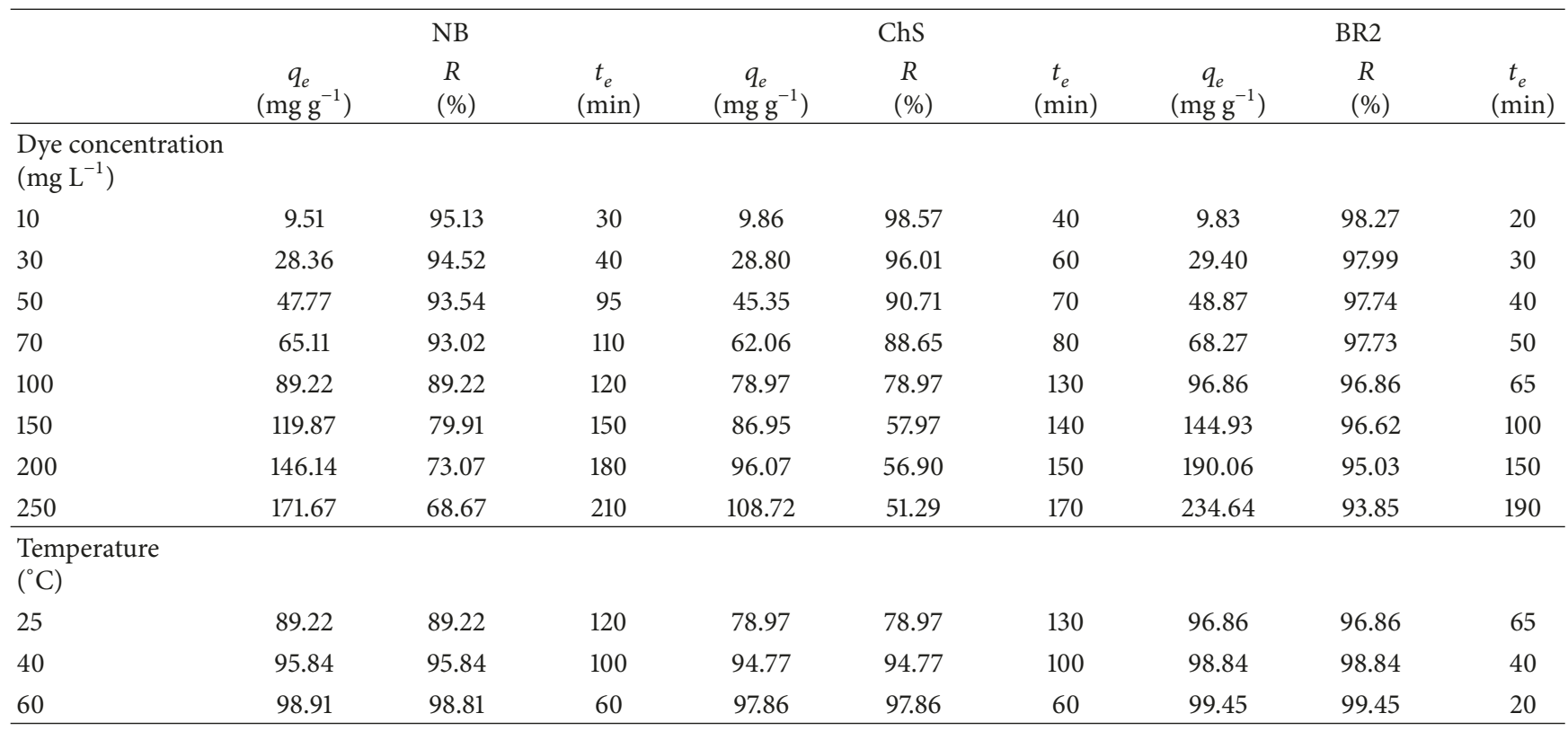

TABLE 4: Comparison of experimental and calculated $q_{e}$ values and rate constants for adsorption of NB, ChS, and BR2 dyes on PM-4 nanocomposites.

\begin{tabular}{|c|c|c|c|c|c|c|c|c|c|c|c|}
\hline \multirow{2}{*}{ Dye } & \multirow{2}{*}{$\begin{array}{l}\text { Temp } \\
\left({ }^{\circ} \mathrm{C}\right)\end{array}$} & \multirow{2}{*}{$\begin{array}{c}q_{e, \exp } \\
\left(\mathrm{mgg}^{-1}\right)\end{array}$} & \multicolumn{3}{|c|}{$\begin{array}{c}\text { First-order } \\
\text { kinetic model }\end{array}$} & \multicolumn{3}{|c|}{$\begin{array}{l}\text { Second-order } \\
\text { kinetic model }\end{array}$} & \multicolumn{3}{|c|}{$\begin{array}{l}\text { Intraparticle } \\
\text { diffusion }\end{array}$} \\
\hline & & & $\begin{array}{c}q_{e, \mathrm{calc}} \\
\left(\mathrm{mg} \cdot \mathrm{g}^{-1}\right)\end{array}$ & $\begin{array}{l}k_{1} \cdot 10^{3} \\
\left(\min ^{-1}\right)\end{array}$ & $R^{2}$ & $\begin{array}{c}q_{e, \mathrm{calc}} \\
\left(\mathrm{mg} \cdot \mathrm{g}^{-1}\right)\end{array}$ & $\begin{array}{c}k_{2} \cdot 10^{4} \\
\left(\mathrm{~g} \cdot \mathrm{mg}^{-1} \cdot \mathrm{min}^{-1}\right)\end{array}$ & $R^{2}$ & $\begin{array}{c}k_{i} \\
\left(\mathrm{mg} \cdot \mathrm{g}^{-1} \cdot \min ^{-0.5}\right)\end{array}$ & $L$ & $R^{2}$ \\
\hline \multirow{3}{*}{ NB } & 25 & 89.22 & 83.27 & 30.77 & 0.9851 & 93.63 & 5.45 & 0.9994 & 9.71 & 5.40 & 0.9603 \\
\hline & 40 & 95.84 & 69.51 & 38.17 & 0.9491 & 102.99 & 9.57 & 0.9987 & 10.07 & 12.75 & 0.9435 \\
\hline & 60 & 98.91 & 59.65 & 63.56 & 0.9579 & 104.28 & 21.11 & 0.9996 & 10.27 & 33.95 & 0.9822 \\
\hline \multirow{3}{*}{ ChS } & 25 & 79.49 & 68.06 & 28.95 & 0.9753 & 80.81 & 7.85 & 0.9992 & 5.67 & 37.15 & 0.9866 \\
\hline & 40 & 94.77 & 48.33 & 25.75 & 0.9501 & 100.81 & 13.78 & 0.9996 & 6.79 & 40.29 & 0.9629 \\
\hline & 60 & 97.86 & 28.87 & 52.97 & 0.9219 & 101.21 & 66.36 & 0.9999 & 7.01 & 58.67 & 0.9765 \\
\hline \multirow{3}{*}{ BR2 } & 25 & 96.86 & 33.78 & 57.02 & 0.8747 & 99.80 & 39.69 & 0.9996 & 17.99 & 5.58 & 0.9540 \\
\hline & 40 & 98.84 & 15.51 & 49.84 & 0.6774 & 100.00 & 82.24 & 0.9999 & 29.17 & 1.94 & 0.9845 \\
\hline & 60 & 99.45 & 8.071 & 50.36 & 0.6212 & 101.21 & 843.7 & 0.9999 & 32.70 & 4.55 & 0.9673 \\
\hline
\end{tabular}

In adsorption systems, there is the possibility of intraparticle diffusion being the rate-limiting step. When applying intraparticle diffusion model, the plots had two portions which means that the intraparticle diffusion is not the rate determining step of the adsorption [38].

The plots had the same shapes (Figure 7), a linear initial portion in which the intraparticle diffusion is the ratecontrolling step, followed by a plateau where intraparticle diffusion slows down [23].

The plots did not pass through the origin and the values of the intercept were significantly different from zero, and larger intercepts indicate that contribution of surface adsorption was higher in rate-controlling step. Moreover, the value of intraparticle parameter $k_{i}$ increases with increasing temperature. All these results suggest that adsorption involved diffusion of the particles and film diffusion but was not the only rate-controlling step.
3.4. Adsorption Isotherms. Equilibrium adsorption studies were carried out for a better understanding of the adsorption process.

The experimental data obtained at equilibrium was analyzed with Freundlich, Langmuir, Sips, and Redlich-Peterson adsorption models.

$$
\begin{aligned}
& q_{e}=K_{F} C_{e}^{1 / n} \\
& q_{e}=\frac{q_{m} K_{L} C_{e}}{1+K_{L} C_{e}} \\
& q_{e}=\frac{q_{m} K_{S} C_{e}^{1 / n}}{1+K_{S} C_{e}^{1 / n}} \\
& q_{e}=\frac{K_{\mathrm{RP}} C_{e}}{1+\alpha_{\mathrm{RP}} C_{e}^{\beta}},
\end{aligned}
$$



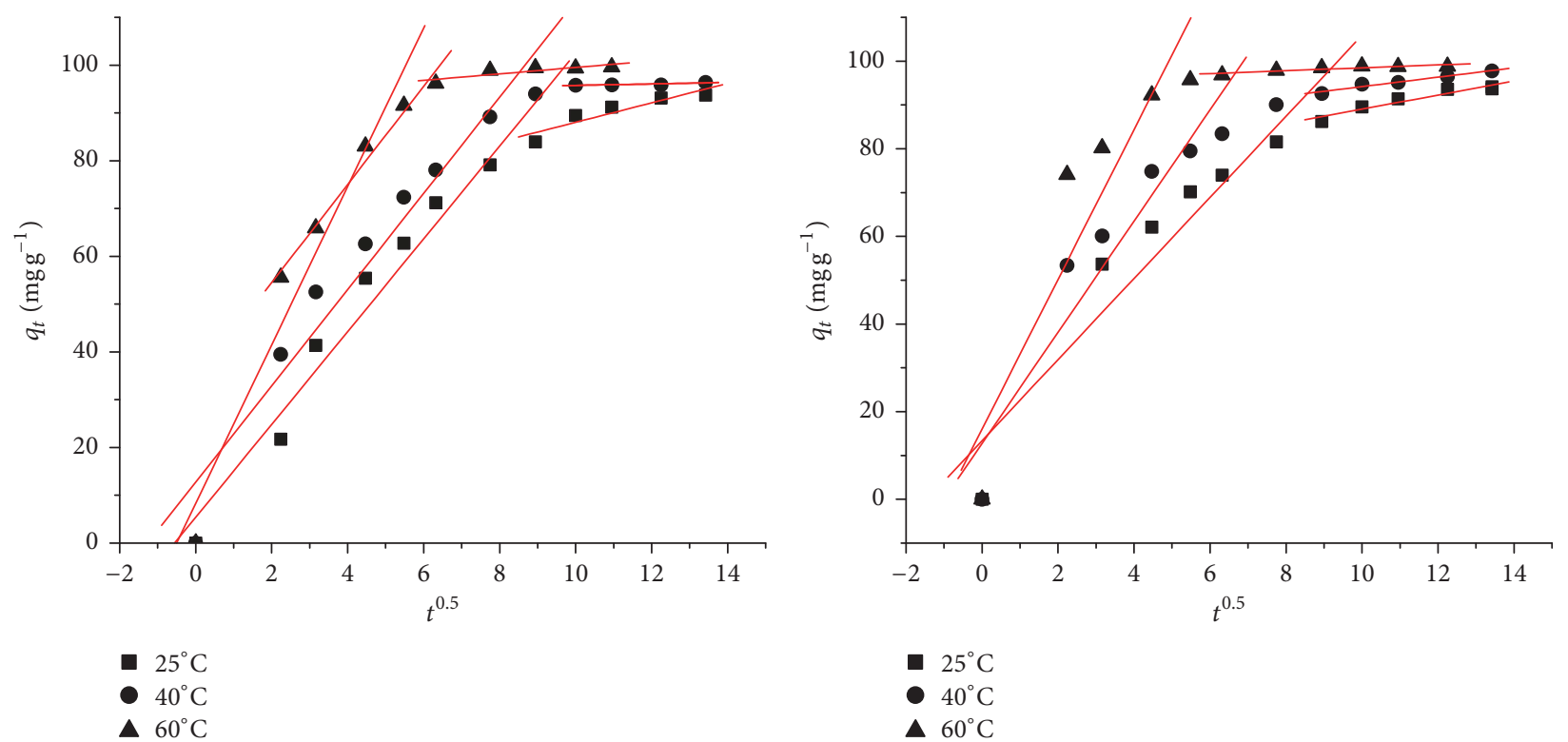

(a)

(b)

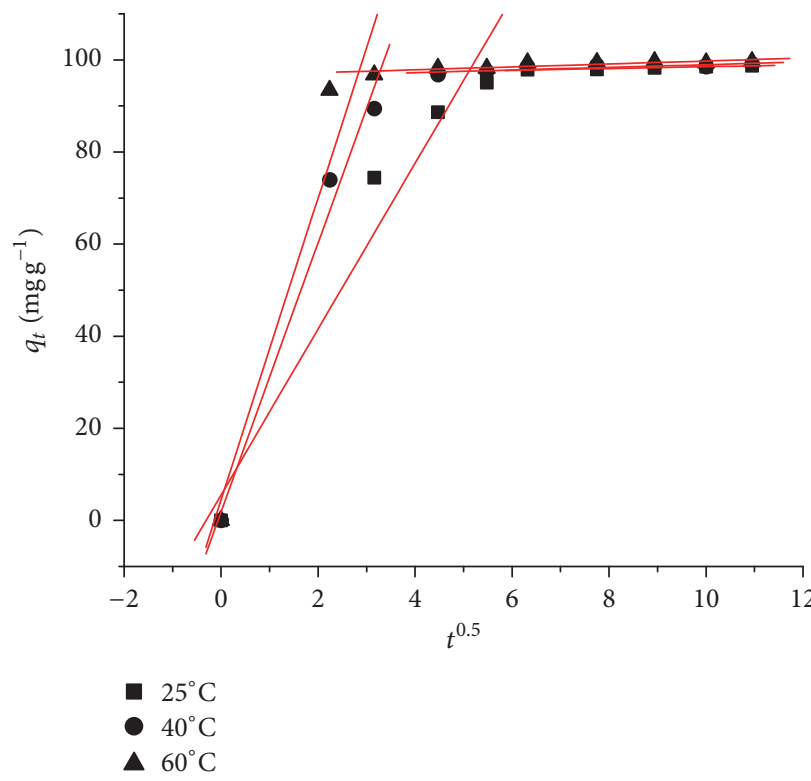

(c)

FIGURE 7: Intraparticle diffusion model applied for adsorption of (a) NB, (b) ChS, and (c) BR2 on PM-4 nanocomposites.

where $q_{e}$ is the equilibrium solid phase concentration, $C_{e}$ is the dye concentration at equilibrium, $K_{F}$ is the constant of Freundlich isotherm, the Freundlich exponent (dimensionless), $K_{L}$ is the constant of Langmuir isotherm, $q_{m}$ is the maximum adsorption capacity of adsorbent, $K_{S}$ is Sips constant related to affinity constant, $K_{\mathrm{RP}}$ is the constant of RedlichPeterson isotherm, $\alpha_{\mathrm{RP}}$ is the Redlich-Peterson constant, and $\beta$ is the Redlich-Peterson exponent (dimensionless) $(0<\beta<$ 1).

The analysis of the experimental data and determination of the parameters which describe the theoretical models were performed, and the main statistical criteria were the squared multiple regression coefficient $\left(R^{2}\right)$ and the chisquare analysis $\left(\chi^{2}\right)[38]$ :

$$
\chi^{2}=\sum \frac{\left(q_{e}-q_{e, m}\right)^{2}}{q_{e, m}},
$$

where $q_{e}$ is the equilibrium capacity $(\mathrm{mg} / \mathrm{g}$ ) obtained from experimental data and $q_{e, m}$ is the equilibrium capacity obtained by calculating from the model (mg/g).

The calculated parameters based on the isotherms models are listed in Table 5. 


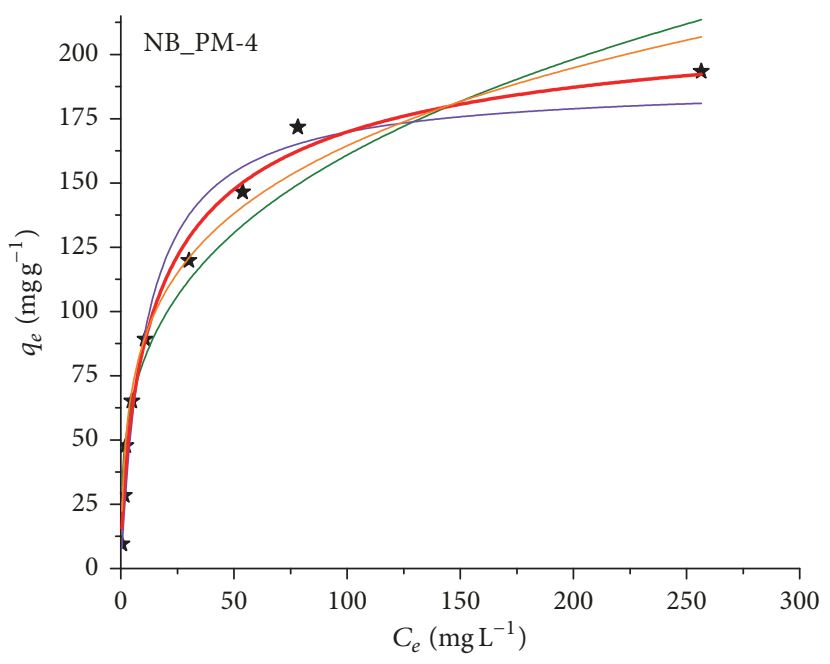

$\star \quad$ Experimental data

— Freundlich; $R^{2}=0.9391$

L Langmuir; $R^{2}=0.9711$

- Sips; $R^{2}=0.9907$

- Redlich-Peterson; $R^{2}=0.9721$

(a)

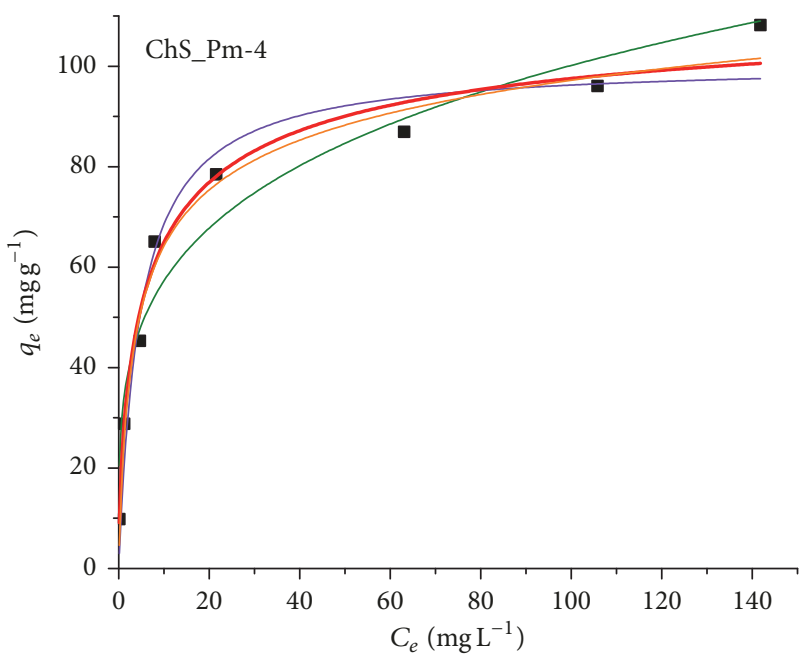

- Experimental data

- Freundlich; $R^{2}=0.9522$

L Langmuir; $R^{2}=0.9609$

- Sips; $R^{2}=0.9861$

Redlich-Peterson; $R^{2}=0.9807$

(b)

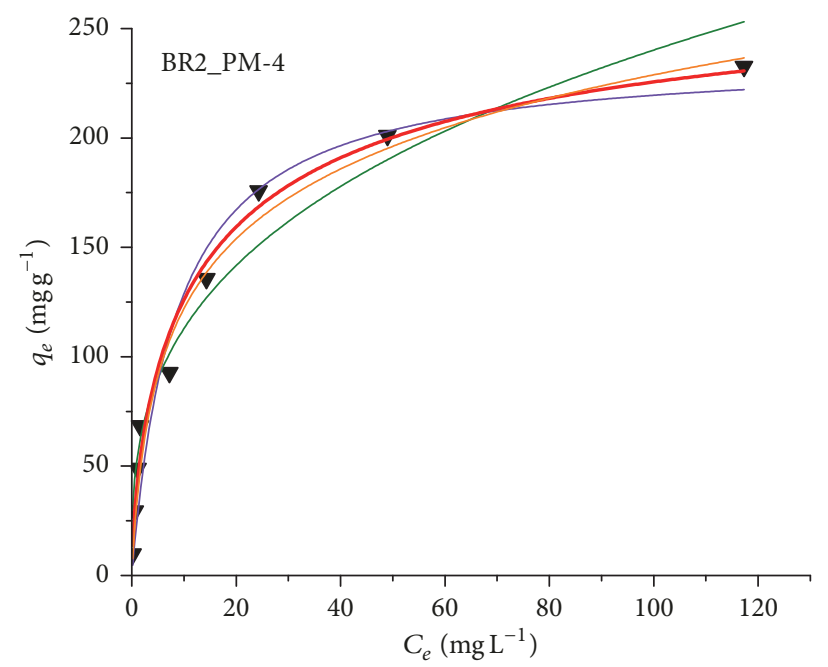

$\begin{array}{ll} & \text { Experimental data } \\ & \text { Freundlich; } R^{2}=0.9602 \\ - & \text { Langmuir; } R^{2}=0.9569 \\ & \text { Sips; } R^{2}=0.9859 \\ & \text { Redlich-Peterson; } R^{2}=0.9795\end{array}$

(c)

FIGURE 8: Isotherms plots for the adsorption of (a) NB, (b) ChS, and (c) BR2 on PM-4.

The best isotherm model that fits with the experimental data was the Sips isotherm model (Figure 8).

That means that an adsorption process is going on after a combined model of Freundlich and Langmuir: diffused adsorption on low dye concentration and a monomolecular adsorption with a saturation value, at high adsorbate concentrations [38]. The maximum adsorption capacity of the PM-4 was determined from the sorption isotherms curves and compared with other results in Table 6.
The magnetite/carbon nanocomposites PM-4 showed a higher affinity for BR2 adsorption than that of NB and ChS in single dye solution.

Thermodynamic Studies. The results obtained using the Sips model were used to calculate the thermodynamic parameters for the adsorption process [18]. Gibb's free energy $\left(\Delta G^{0}\right)$ was calculated using the following equation:

$$
\Delta G^{0}=-R T \ln K_{S}
$$


TABLE 5: Constants and correlation coefficients of adsorption isotherm models.

\begin{tabular}{|c|c|c|c|c|}
\hline \multirow{2}{*}{ Models } & \multirow{2}{*}{ Parameter } & \multicolumn{3}{|c|}{ Dyes } \\
\hline & & NB & ChS & $\mathrm{BR} 2$ \\
\hline \multirow{4}{*}{ Freundlich } & $K_{F}\left(\mathrm{mg} \mathrm{g}^{-1}\left(\mathrm{mg} \mathrm{L}^{-1}\right)^{-1 / n}\right)$ & 40.28 & 32.76 & 53.05 \\
\hline & $n$ & 3.326 & 4.121 & 3.049 \\
\hline & $R^{2}$ & 0.9391 & 0.9522 & 0.9602 \\
\hline & $\chi^{2}$ & 292.77 & 65.62 & 287.58 \\
\hline \multirow{4}{*}{ Langmuir } & $q_{m}\left(\mathrm{mg} \mathrm{g}^{-1}\right)$ & 188.96 & 100.77 & 238.17 \\
\hline & $K_{L}\left(\mathrm{~L} \mathrm{mg}^{-1}\right)$ & 0.089 & 0.213 & 0.118 \\
\hline & $R^{2}$ & 0.9711 & 0.9609 & 0.9569 \\
\hline & $x^{2}$ & 138.98 & 53.59 & 311.63 \\
\hline \multirow{5}{*}{ Sips } & $q_{m}\left(\mathrm{mg} \mathrm{g}^{-1}\right)$ & 223.82 & 114.68 & 286.91 \\
\hline & $K_{S}\left(\left(\mathrm{mg} \mathrm{L}^{-1}\right)^{-1 / n}\right)$ & 0.051 & 0.152 & 0.069 \\
\hline & $n$ & 1.424 & 1.563 & 1.489 \\
\hline & $R^{2}$ & 0.9907 & 0.9861 & 0.9859 \\
\hline & $\chi^{2}$ & 52.57 & 29.59 & 118.98 \\
\hline \multirow{5}{*}{ Redlich-Peterson } & $K_{\mathrm{RP}}\left(\mathrm{L} \mathrm{g}^{-1}\right)$ & 85.37 & 35.46 & 50.11 \\
\hline & $\alpha_{\mathrm{RP}}\left(\mathrm{mg} \mathrm{L}^{-1}\right)^{-\beta}$ & 1.486 & 0.577 & 0.462 \\
\hline & $\beta$ & 0.767 & 0.895 & 0.828 \\
\hline & $R^{2}$ & 0.9721 & 0.9807 & 0.9795 \\
\hline & $\chi^{2}$ & 157.21 & 31.75 & 172.32 \\
\hline
\end{tabular}

TABLE 6: Adsorption capacities of magnetic nanocomposites for the adsorption of dyes from aqueous solutions.

\begin{tabular}{|c|c|c|c|}
\hline Dye & Adsorbent & $q_{t}(\mathrm{mg} / \mathrm{g})$ & Reference \\
\hline Chromazurol S & PEI-Halloysite & 68.40 & {$[10]$} \\
\hline Chromazurol S & Halloysite nanotubes & 20.40 & {$[11]$} \\
\hline Nylosan Blue & Thermally treated rice husk & 30.00 & {$[12]$} \\
\hline Nylosan Blue & Acid-activated Bentonite & 119.10 & [13] \\
\hline Safranin $\mathrm{T}$ & Kaolinite clay & 16.23 & [14] \\
\hline Metyl Orange & $\mathrm{CoFe}_{2} \mathrm{O}_{4}$-reduced graphene oxide nanocomposites & 263.00 & {$[15]$} \\
\hline Safranin $\mathrm{T}$ & $\mathrm{G}-\mathrm{SO}_{3} \mathrm{H} / \mathrm{Fe}_{3} \mathrm{O}_{4}$ & 199.30 & {$[16]$} \\
\hline Nylosan Blue & Magnetite/carbon nanocomposites & 223.82 & [This study] \\
\hline Chromazurol S & Magnetite/carbon nanocomposites & 114.68 & [This study] \\
\hline Safranin $\mathrm{T}$ & Magnetite/carbon nanocomposites & 286.91 & [This study] \\
\hline
\end{tabular}

and both enthalpy $\left(\Delta H^{0}\right)$ and entropy $\left(\Delta S^{0}\right)$ were determined from van' Hoff equation:

$$
\Delta G^{0}=\Delta H^{0}-T \Delta S^{0}
$$

where $R$ is the universal gas constant $\left(8.314 \mathrm{~J} \mathrm{~K}^{-1} \mathrm{~mol}^{-1}\right)$, $T$ is the absolute temperature, and $K_{S}$ represents the Sips equilibrium constant, obtained from the isotherm plots. $\Delta H^{0}$ and $\Delta S^{0}$ values can be calculated from the slope and intercept of the linear plot of $\ln K_{S}$ versus $1 / T$.

The $\Delta G^{0}$ values are negative indicating that the adsorption is a spontaneous process (Table 7). The positive values of $\Delta H^{0}$ suggest the endothermic nature of the process and indicate that the amount adsorbed at equilibrium is increased with increasing temperature. The positive values of $\Delta S^{0}$ reflect an increase in randomness at the solid-solution interface during the dyes adsorption onto PM4 [39].
Adsorbent Stability and Reusability. A promising adsorbent for large-scale wastewater treatment must present a very good adsorption capacity, easy separation, and high stability. To validate the reusability of the magnetic adsorbent, seven cycles of consecutive adsorption-desorption were carried out at $25^{\circ} \mathrm{C}$ (Figure 9).

The removal efficiency decreased continuously, but it still remained at $68 \%$ in the seventh cycle, indicating the good recycling performance of the used adsorbent (PM-4). The adsorption-desorption studies revealed a greater preference for BR2 compared with other two dyes.

Adsorption in Binary Systems. The optimum conditions obtained for individual adsorption were selected as starting conditions for simultaneous adsorption of dyes from bisorbate systems.

In binary adsorption systems, the primary and coexisting sorbate had the same initial concentration, a mass ratio of $1: 1$, 


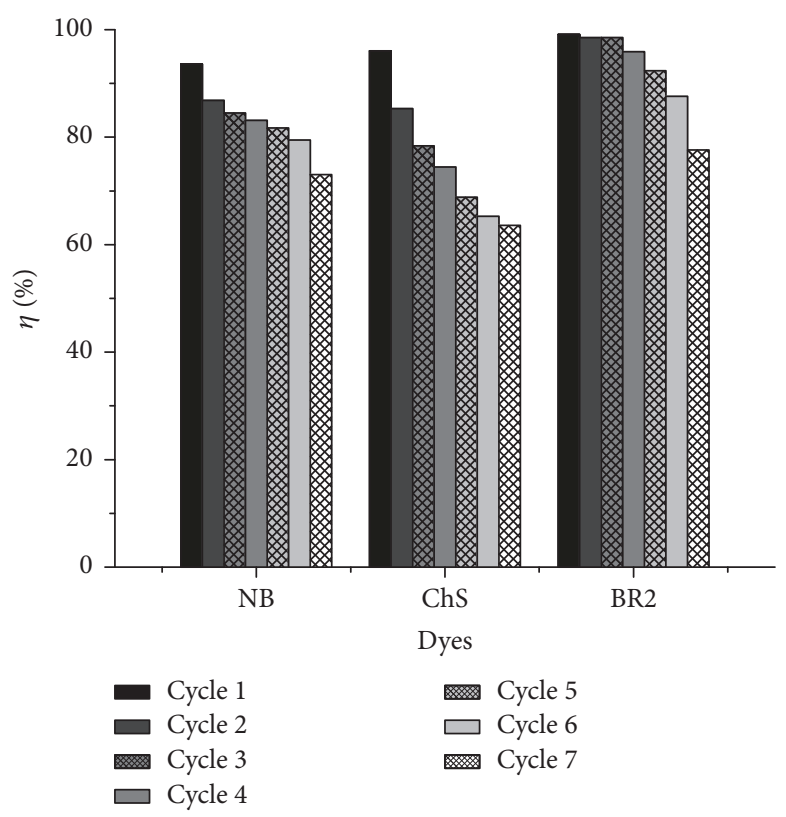

Figure 9: Removal efficiency of PM-4 in seven adsorption-desorption cycles.

TABLE 7: Thermodynamic parameters for the adsorption of investigated dyes on PM-4 nanocomposites.

\begin{tabular}{|c|c|c|c|c|}
\hline Dye & $\begin{array}{c}\text { Temp. } \\
\left({ }^{\circ} \mathrm{C}\right)\end{array}$ & $\begin{array}{c}\Delta G^{0} \\
(\mathrm{~J} / \mathrm{mol})\end{array}$ & $\begin{array}{c}\Delta H^{0} \\
(\mathrm{~J} / \mathrm{mol})\end{array}$ & $\begin{array}{c}\Delta S^{0} \\
(\mathrm{~J} / \mathrm{mol} \cdot \mathrm{K})\end{array}$ \\
\hline \multirow{3}{*}{ NB } & 25 & -7373.08 & \multirow{3}{*}{6053.50} & \multirow{3}{*}{432.99} \\
\hline & 40 & -7744.21 & & \\
\hline & 60 & -8239.05 & & \\
\hline \multirow{3}{*}{ ChS } & 25 & -4667.44 & \multirow{3}{*}{3832.12} & \multirow{3}{*}{274.09} \\
\hline & 40 & -4902.37 & & \\
\hline & 60 & -5215.62 & & \\
\hline \multirow{3}{*}{ BR2 } & 25 & -6624.16 & \multirow{3}{*}{5438.63} & \multirow{3}{*}{389} \\
\hline & 40 & -6957.59 & & \\
\hline & 60 & -7402.16 & & \\
\hline
\end{tabular}

and the experimental studies followed the same procedure as for the single sorbate adsorption experiments.

The concentration of each dye in binary systems was calculated using the following equations [40]:

$$
\begin{aligned}
C_{A} & =\frac{k_{B 2} \cdot A_{1}-k_{B 1} \cdot A_{2}}{k_{A 1} \cdot k_{B 2}-k_{A 2} \cdot k_{B 1}} \\
C_{B} & =\frac{k_{A 1} \cdot A_{2}-k_{A 2} \cdot A_{1}}{k_{A 1} \cdot k_{B 2}-k_{A 2} \cdot k_{B 1}},
\end{aligned}
$$

where $A_{1}, A_{2}$ represent the total absorbance at wavelengths $\lambda_{1 \max }$ and $\lambda_{2 \max }$ and $k_{A 1}, k_{B 1}, k_{A 2}, k_{B 2}$ are the calibration constants for components $A$ and $B$ at $\lambda_{1 \max }$ and $\lambda_{2 \max }$.

Each individual dye spectrum and spectra of binary mixtures of dyes are shown in supplementary file SupFig. 4.

Effect of solution $\mathrm{pH}$ on removal percentage in case of binary systems studied for $100 \mathrm{mg} / \mathrm{L}$ dye concentration, at $25^{\circ} \mathrm{C}$, is presented in Table 8 .
TABLE 8: Effect of solution $\mathrm{pH}$ on dyes removal efficiency in the case of binary system.

\begin{tabular}{lccc}
\hline Dye & & $p H$ & \\
& 2.84 & 6.90 & 10.14 \\
$R(\%)$ & \\
\hline NB (NB + ChS) & 87.38 & 77.21 & 51.11 \\
NB (NB + BR2) & 87.98 & 96.52 & 94.00 \\
\hline ChS (ChS + NB) & 63.50 & 59.17 & 22.60 \\
ChS (ChS + BR2) & 73.08 & 52.82 & 52.37 \\
\hline BR2 (BR2 + NB) & 95.48 & 97.83 & 98.92 \\
BR2 (BR2 + ChS) & 88.29 & 91.76 & 92.82 \\
\hline
\end{tabular}

Even in case of binary systems, in acidic medium, the removal efficiency of PM-4 is higher for anionic dyes: NB and $\mathrm{ChS}$ due to electrostatic attraction between negatively charged dye molecules and positively charged surface of PM4. At a $\mathrm{pH} \sim 10$, which was the optimum $\mathrm{pH}$ for removal of 
TABLE 9: Effect of initial concentration on dyes removal efficiency for binary systems.

\begin{tabular}{|c|c|c|c|}
\hline \multirow[t]{2}{*}{ Conc $\left(\mathrm{mg} \mathrm{L}^{-1}\right)$} & \multirow{2}{*}{$\begin{array}{c}R \sin .(\%) \\
\mathrm{NB}\end{array}$} & \multicolumn{2}{|c|}{$R$ bin. (\%) } \\
\hline & & $\mathrm{NB}(\mathrm{NB}+\mathrm{RB} 2)^{*}$ & $\mathrm{NB}(\mathrm{NB}+\mathrm{ChS})^{*}$ \\
\hline 30 & 94.52 & 94.24 & 86.40 \\
\hline 100 & 89.22 & 93.98 & 87.38 \\
\hline \multirow[t]{2}{*}{200} & 73.07 & 84.50 & 66.08 \\
\hline & ChS & $\mathrm{ChS}(\mathrm{ChS}+\mathrm{BR} 2)^{*}$ & $\mathrm{ChS}(\mathrm{ChS}+\mathrm{NB})^{*}$ \\
\hline 30 & 96.01 & 92.72 & 90.18 \\
\hline 100 & 78.97 & 90.08 & 70.33 \\
\hline \multirow[t]{2}{*}{200} & 56.90 & 89.20 & 63.50 \\
\hline & BR2 & $\mathrm{BR} 2(\mathrm{BR} 2+\mathrm{NB})^{* *}$ & $\mathrm{BR} 2(\mathrm{BR} 2+\mathrm{ChS})^{* *}$ \\
\hline 30 & 97.99 & 94.30 & 93.80 \\
\hline 100 & 96.86 & 92.82 & 93.92 \\
\hline 200 & 95.03 & 88.30 & 93.18 \\
\hline
\end{tabular}

${ }^{*}$ Determined at $\mathrm{pH} 2.68 .{ }^{* *}$ Determined at $\mathrm{pH} 10.14$.

BR2 dye in single system, the adsorption of BR2 (cationic dye) from binary systems is favored in comparison with adsorption of $\mathrm{NB}$ or $\mathrm{ChS}$ (anionic dyes).

The effect of the initial dye concentrations on the percentage removal in case of binary (bin.) systems was investigated using $20 \mathrm{ml}$ of dye solution and $20 \mathrm{mg} / \mathrm{L} \mathrm{PM}-4$ at $25^{\circ} \mathrm{C}$, for $200 \mathrm{~min}$, and results are presented in Table 9. Three different binary mixtures were investigated $\mathrm{NB}+\mathrm{BR} 2, \mathrm{ChS}$ $+\mathrm{BR} 2$, and $\mathrm{NB}+\mathrm{ChS}$, at three different concentrations: a lower one consists of $30 \mathrm{mg} \mathrm{L}^{-1}$ of both dyes, a higher initial concentration consists of $200 \mathrm{mg} \mathrm{L}^{-1}$ of both dyes, and a middle concentration value is $100 \mathrm{mg} \mathrm{L}^{-1}$ of both dyes.

As it was expected, the removal percentage of dyes decreased in binary systems when compared with the adsorption in single-solute systems. By increasing concentration of dyes in binary systems, the removal efficiency decreased, similar with the case of single component. It is seen that adsorption of $\mathrm{BR} 2$ was slightly affected by the presence of $\mathrm{NB}$ or ChS in BR2 + NB and BR2 + ChS binary solutions. The adsorption of NB and ChS dyes in binary systems containing BR2 as copollutant was improved compared with the single systems. Similar results were obtained for other binary systems by Deng et al. [41], Yang et al. [42], and An et al. [28].

In order to determine the effectiveness of the absorbent investigated (PM-4) under field conditions, that is, $\mathrm{pH}$ of the solutions (6.90 for $\mathrm{NB}+\mathrm{BR} 2,7.09$ for $\mathrm{ChS}+\mathrm{BR} 2$, and 7.90 for $\mathrm{NB}+\mathrm{ChS}$ ) at $25^{\circ} \mathrm{C}$, we have extended the analysis for the dye concentration of $100 \mathrm{mg} / \mathrm{L}$. Results are presented in Figure 10.

As can be observed even at the natural $\mathrm{pH}$ of the BR2 dye solution, sorbent PM-4 demonstrates a high selectivity for BR2 in binary systems. The removal percentage of NB decreased in binary system $\mathrm{NB}+\mathrm{ChS}$ compared with its removal in single system indicated that NB was affected by the presence of ChS during the competitive adsorption. The most affected in binary system was ChS dye, the removal efficiency of ChS decreasing due to competition between the ChS and NB or BR2 onto MNC PM-4.

\section{Conclusions}

In this paper, magnetic nanoparticles embedded within a matrix of activated carbon were tested as adsorbent for dyes removal from single and binary systems.

The adsorption capacities decreased for $\mathrm{NB}$ and $\mathrm{ChS}$ and increased for BR2 with increasing $\mathrm{pH}$ value. The removal efficiency of pollutants increased with increasing the carbon content, with initial concentration of the pollutants, the dose of MNC, and temperature. Kinetic studies revealed that adsorption of investigated dyes followed a pseudo-secondorder kinetic in single dye solution. The application of intraparticle diffusion model demonstrates that the surface diffusion and the intraparticle diffusion occur in parallel during the adsorption process. The experimental data were well correlated by the Sips adsorption model, and in single systems, the maximum adsorption capacities were $223.82 \mathrm{mg} \mathrm{g}^{-1}$ for $\mathrm{NB}, 114.68 \mathrm{mg} \mathrm{g}^{-1}$ for $\mathrm{ChS}$, and $286.91 \mathrm{mg} \mathrm{g}^{-1}$ for BR2, respectively. Thermodynamic analysis showed that adsorption of investigated dyes on MNC was favorable, spontaneous, and endothermic. Even after seven adsorption-desorption cycles, the magnetite/carbon nanocomposites still present a good efficiency (greater than 65\%) for dyes removal from aqueous solution, indicating the possible industrial application of MNC. In binary systems, the removal efficiency decreased due to competitive effect, but still sorbent PM- 4 demonstrates a high selectivity for BR2 in binary systems. The obtained results were compared with the previously reported data on different adsorbents for the same dyes and the selected magnetite nanocomposite from this work demonstrates its superiority and the potential as a new efficient adsorbent for the removal of dyes in binary systems from aqueous solutions.

Considering the facile and low-cost characteristics of the synthesis method, magnetic separation efficiency and simplicity, and the stability and reusability in several adsorptionsdesorption cycles, the magnetite/carbon nanocomposites 


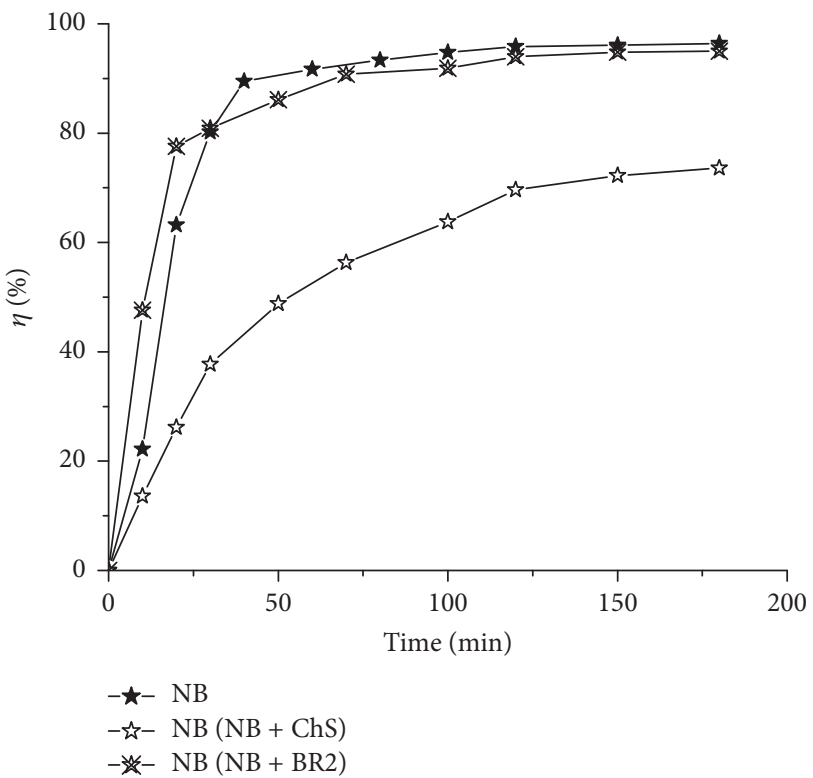

(a)

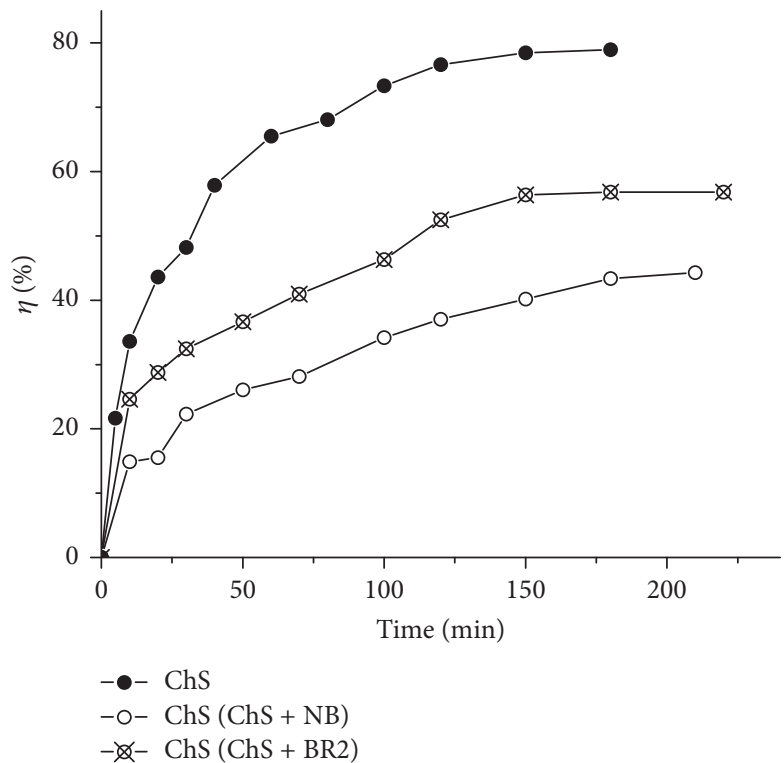

(b)

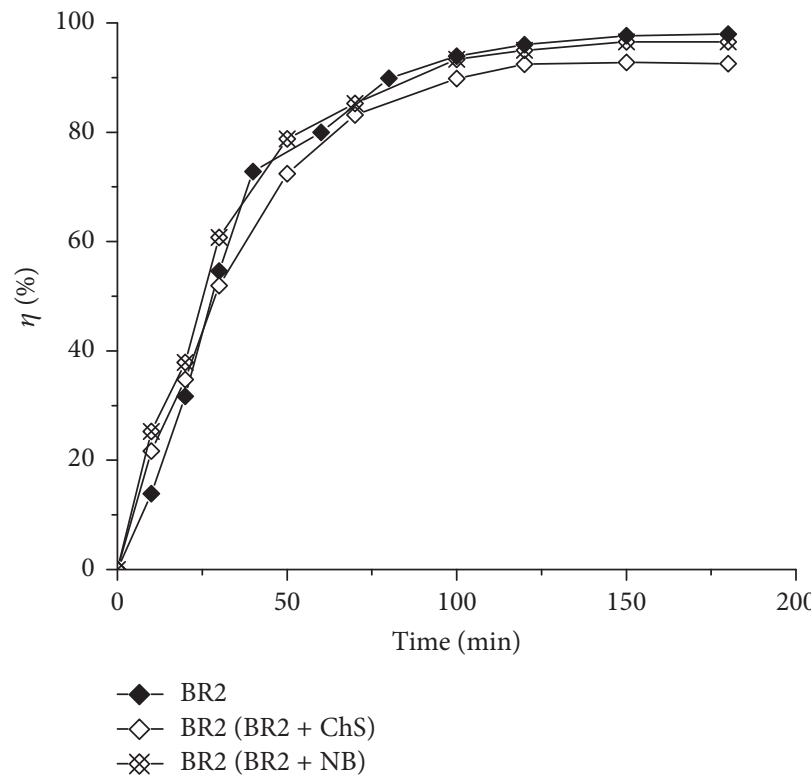

(c)

Figure 10: The kinetics of competitive adsorption of NB, ChS, and BR2 in single- and binary-solute systems $\left(100 \mathrm{mg} / \mathrm{L}\right.$, adsorbent $2 \mathrm{~g} / \mathrm{L}, 25^{\circ} \mathrm{C}$, $\mathrm{pH} 7.4$ for NB, 7.1 for ChS, and 6.7 for BR2).

used in this study are versatile and promising candidates for the removal of dyes from aqueous solutions.

\section{Conflicts of Interest}

The authors declare that they have no conflicts of interest.

\section{Acknowledgments}

This work was supported by a grant of the Romanian National Authority for Scientific Research and Innovation, CNCSUEFISCDI, Project no. PN-II-RU-TE-2014-4-1319, and by
Program 2 of the Institute of Chemistry Timişoara of Romanian Academy (Research Project 2.4.)

\section{Supplementary Materials}

SuppFig. 1: calibration curve for ChS, NB, and BR2 dyes. SuppFig. 2: adsorption-desorption isotherms of samples PM1, PM-3, PM-4, PM-5, and P-6 [10]. SuppFig. 3: samples of dyes solution before and after adsorption. SuppFig. 4: individual dye spectra and spectra of binary mixtures of dyes. (Supplementary Materials) 


\section{References}

[1] M. Ashrafi, M. Arab Chamjangali, G. Bagherian, and N. Goudarzi, "Application of linear and non-linear methods for modeling removal efficiency of textile dyes from aqueous solutions using magnetic $\mathrm{Fe} 3 \mathrm{O} 4$ impregnated onto walnut shell," Spectrochimica Acta Part A: Molecular and Biomolecular Spectroscopy, vol. 171, pp. 268-279, 2017.

[2] R. K. Vital, K. V. N. Saibaba, K. B. Shaik, and R. Gopinath, "Gopinath, Dye removal by adsorption: a review," Journal of Bioremediation \& Biodegradation, vol. 7, no. 371, 2016.

[3] N. M. Mahmoodi and S. Soltani-Gordefaramarzi, "Dye removal from single and quaternary systems using surface modified nanoparticles: Isotherm and kinetics studies," Progress in Color, Colorants and Coatings, vol. 9, no. 2, pp. 85-97, 2016.

[4] R. Tang, C. Dai, C. Li, W. Liu, S. Gao, and C. Wang, "Removal of Methylene Blue from Aqueous Solution Using Agricultural Residue Walnut Shell: Equilibrium, Kinetic, and Thermodynamic Studies," Journal of Chemistry, vol. 2017, Article ID 8404965, 2017.

[5] W. T. Al-Rubayee, O. F. Abdul-Rasheed, and N. M. Ali, "Preparation of a Modified Nanoalumina Sorbent for the Removal of Alizarin Yellow R and Methylene Blue Dyes from Aqueous Solutions," Journal of Chemistry, vol. 2016, Article ID 4683859, 2016.

[6] L. Kong, X. Gan, A. L. B. Ahmad et al., "Design and synthesis of magnetic nanoparticles augmented microcapsule with catalytic and magnetic bifunctionalities for dye removal," Chemical Engineering Journal, vol. 197, pp. 350-358, 2012.

[7] H. R. Lotfi Zadeh Zhad, F. Aboufazeli, O. Sadeghi, V. Amani, E. Najafi, and N. Tavassoli, "Tris(2-Aminoethyl)aminefunctionalized Femagnetic nanoparticles as a selective sorbent for separation of silver and gold ions in different pHs," Journal of Chemistry, Article ID 482793, 2013.

[8] Y. Liu, G. Zeng, L. Tang et al., "Highly effective adsorption of cationic and anionic dyes on magnetic $\mathrm{Fe} / \mathrm{Ni}$ nanoparticles doped bimodal mesoporous carbon," Journal of Colloid and Interface Science, vol. 448, pp. 451-549, 2015.

[9] R. Ianoş, C. Pǎcurariu, and G. Mihoc, "Magnetite/carbon nanocomposites prepared by an innovative combustion synthesis technique - Excellent adsorbent materials," Ceramics International, vol. 40, no. 8, pp. 13649-13657, 2014.

[10] Y. Zhao, E. Abdullayev, A. Vasiliev, and Y. Lvov, "Halloysite nanotubule clay for efficient water purification," Journal of Colloid and Interface Science, vol. 406, no. 15, pp. 121-129, 2013.

[11] Y. Zhao, E. Abdullayev, and Y. Lvov, "Nanotubular halloysite clay as efficient water filtration system for removal of cationic and anionic dyes," in Proceedings of the 2nd International Conference on Structural Nano Composites, NANOSTRUC 2014, May 2014.

[12] G. K. Jayatunga, "Rice husk based adsorbents for dye removal from wastewater," 2009, http://dl.lib.mrt.ac.lk/handle/123/1832.

[13] A. S. Özcan and A. Özcan, "Adsorption of acid dyes from aqueous solutions onto acid-activated bentonite," Journal of Colloid and Interface Science, vol. 276, no. 1, pp. 39-46, 2004.

[14] K. O. Adebowale, B. I. Olu-Owolabi, and E. C. Chigbundu, "Removal of Safranin-O from Aqueous Solution by Adsorption onto Kaolinite Clay," Journal of Encapsulation and Adsorption Sciences (JEAS), vol. 04, no. 03, pp. 89-104, 2014.

[15] Z. J. Song, W. Ran, and F. Y. Wei, "One-step approach for the synthesis of CoFe2o4@rGO core-shell nanocomposites as efficient adsorbent for removal of organic pollutants," Water Science and Technology, vol. 75, no. 2, pp. 397-405, 2017.
[16] R. K. Gautam and M. C. Chattopadhyaya, Nanomaterials for wastewater remediation (Butterworth-Heinemann, vol. cap 6, Taylor \& Francis Group, 2016.

[17] M. Fayazi, D. Afzali, M. A. Taher, A. Mostafavi, and V. K. Gupta, "Removal of Safranin dye from aqueous solution using magnetic mesoporous clay: Optimization study," Journal of Molecular Liquids, vol. 212, pp. 675-685, 2015.

[18] S. G. Muntean, O. Paska, S. Coseri, G. M. Simu, M. E. Grad, and G. Ilia, "Evaluation of a functionalized copolymer as adsorbent on direct dyes removal process: Kinetics and equilibrium studies," Journal of Applied Polymer Science, vol. 127, no. 6, pp. 4409-4421, 2013.

[19] E. Tombácz, E. Illés, A. Majzik, A. Hajdú, N. Rideg, and M. Szekeres, "Ageing in the inorganic nanoworld: Example of magnetite nanoparticles in aqueous medium," Croatica Chemica Acta, vol. 80, no. 3-4, pp. 503-515, 2007.

[20] R. Istratie, M. Stoia, C. Păcurariu, and C. Locovei, "Single and simultaneous adsorption of methyl orange and phenol onto magnetic iron oxide/carbon nanocomposites," Arabian Journal of Chemistry, 2015.

[21] P. K. Malik, "Dye removal from wastewater using activated carbon developed from sawdust: adsorption equilibrium and kinetics," Journal of Hazardous Materials, vol. 113, no. 1-3, pp. 81-88, 2004.

[22] D. Schimmel, K. C. Fagnani, J. B. O. Dos Santos, M. A. S. D. Barros, and E. A. Da Silva, "Adsorption of turquoise blue qg reactive dye on commercial activated carbon in batch reactor: Kinetic and equilibrium studies," Brazilian Journal of Chemical Engineering, vol. 27, no. 2, pp. 289-298, 2010.

[23] C. Pǎcurariu, O. Paşka, R. Ianoş, and S. G. Muntean, "Effective removal of methylene blue from aqueous solution using a new magnetic iron oxide nanosorbent prepared by combustion synthesis," Clean Technologies and Environmental Policy, vol. 18, no. 3, pp. 705-715, 2016.

[24] I. Shah, R. Adnan, W. S. W. Ngah, and N. Mohamed, "Iron impregnated activated carbon as an efficient adsorbent for the removal of methylene blue: Regeneration and kinetics studies," PLoS ONE, vol. 10, no. 4, Article ID e0122603, 2015.

[25] H. Sun, L. Cao, and L. Lu, "Magnetite/reduced graphene oxide nanocomposites: one step solvothermal synthesis and use as a novel platform for removal of dye pollutants," Nano Research, vol. 4, no. 6, pp. 550-562, 2011.

[26] M. R. Patil and V. S. Shrivastava, "Adsorption of malachite green by polyaniline-nickel ferrite magnetic nanocomposite: an isotherm and kinetic study," Applied Nanoscience, vol. 5, no. 7, pp. 809-816, 2015.

[27] S. D. Abkenar, "Application of magnetic-modified Fe3O4 nanoparticles for removal of crystal violet from aqueous solution: kinetic, equilibrium and thermodynamic studies," J. Appl. Chem. Res, vol. 10, no. 1, pp. 65-74, 2016.

[28] S. An, X. Liu, L. Yang, and L. Zhang, "Enhancement removal of crystal violet dye using magnetic calcium ferrite nanoparticle: Study in single- and binary-solute systems," Chemical Engineering Research and Design, vol. 94, pp. 726-735, 2015.

[29] S. G. Muntean, M. E. Rădulescu-Grad, and P. Sfârloagǎ, "Dye adsorbed on copolymer, possible specific sorbent for metal ions removal," RSC Advances, vol. 4, no. 52, pp. 27354-27362, 2014.

[30] M. K. Satapathy, P. Banerjee, and P. Das, "Plant-mediated synthesis of silver-nanocomposite as novel effective azo dye adsorbent," Applied Nanoscience, vol. 5, no. 1, pp. 1-9, 2015.

[31] C. Vîrlan, R. G. Ciocârlan, T. Roman, D. Gherca, N. Cornei, and A. Pui, "Studies on adsorption capacity of cationic dyes on 
several magnetic nanoparticles," Acta Chemica Iasi, vol. 21, no. 1, 2013.

[32] D. Robati, B. Mirza, M. Rajabi et al., "Removal of hazardous dyes-BR 12 and methyl orange using graphene oxide as an adsorbent from aqueous phase," Chemical Engineering Journal, vol. 284, pp. 687-697, 2016.

[33] X. Zhao, S. Liu, Z. Tang et al., "Synthesis of magnetic metalorganic framework (MOF) for efficient removal of organic dyes from water," Scientific Reports, vol. 5, Article ID 11849, 2015.

[34] S. G. Muntean, G. M. Simu, L. Kurunczi, and Z. Szabadai, "Investigation of the aggregation of three disazo direct dyes by UV-vis spectroscopy and mathematical analysis," CHEMISTRY MAGAZINE, vol. 60, no. 2, pp. 152-155, 2009.

[35] S. G. Muntean, G. M. Simu, L. Kurunczi, and Z. Szabadai, "Experimental and mathematical study of the aggregation of a green trisazo direct dye," CHEMISTRY MAGAZINE, vol. 59, no. 8, pp. 894-897, 2008.

[36] T. Wang, P. Zhao, N. Lu, H. Chen, C. Zhang, and X. Hou, "Facile fabrication of Fe3O4/MIL-101(Cr) for effective removal of acid red 1 and orange G from aqueous solution," Chemical Engineering Journal, vol. 295, pp. 403-413, 2016.

[37] D. Chen, Z. Zeng, Y. Zeng, F. Zhang, and M. Wang, "Removal of methylene blue and mechanism on magnetic $\gamma$-Fe2O3/SiO2 nanocomposite from aqueous solution," Water Resources and Industry, vol. 15, pp. 1-13, 2016.

[38] S. G. Muntean, A. Todea, M. E. Radulescu-Grad, and A. Popa, "Decontamination of colored wastewater using synthetic sorbents," Pure and Applied Chemistry, vol. 86, no. 11, pp. 17711780, 2014.

[39] R. Ahmad and R. Kumar, "Kinetic and thermodynamic studies of brilliant green adsorption onto carbon/iron oxide nanocomposite," Journal of the Korean Chemical Society, vol. 54, no. 1, pp. 125-130, 2010.

[40] N. M. Mahmoodi, R. Salehi, and M. Arami, "Binary system dye removal from colored textile wastewater using activated carbon: Kinetic and isotherm studies," Desalination, vol. 272, no. 1-3, pp. 187-195, 2011.

[41] J.-H. Deng, X.-R. Zhang, G.-M. Zeng, J.-L. Gong, Q.-Y. Niu, and J. Liang, "Simultaneous removal of $\mathrm{Cd}(\mathrm{II})$ and ionic dyes from aqueous solution using magnetic graphene oxide nanocomposite as an adsorbent," Chemical Engineering Journal, vol. 226, pp. 189-200, 2013.

[42] L. Yang, Y. Zhang, X. Liu et al., "The investigation of synergistic and competitive interaction between dye Congo red and methyl blue on magnetic MnFe2O4," Chemical Engineering Journal, vol. 246, pp. 88-96, 2014. 



Physical Chemistry
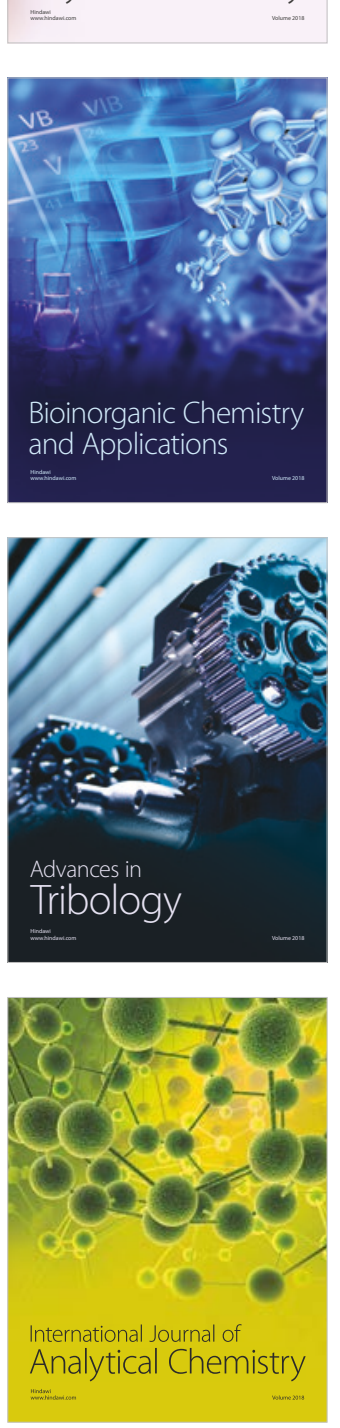

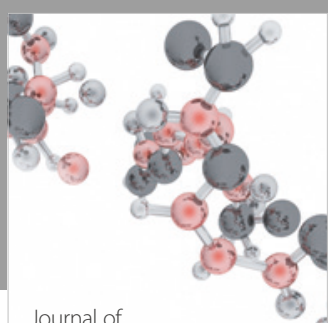

Analytical Methods

in Chemistry

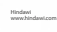

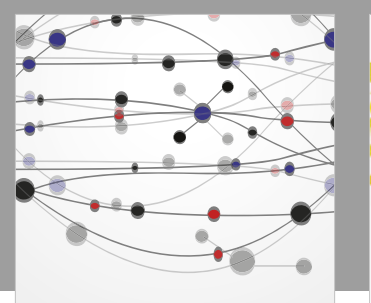

The Scientific World Journal

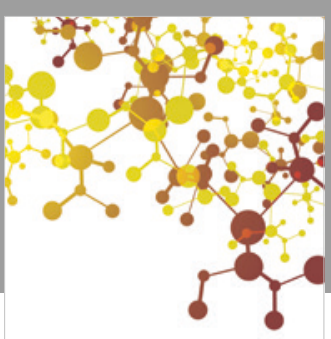

Journal of

Applied Chemistry
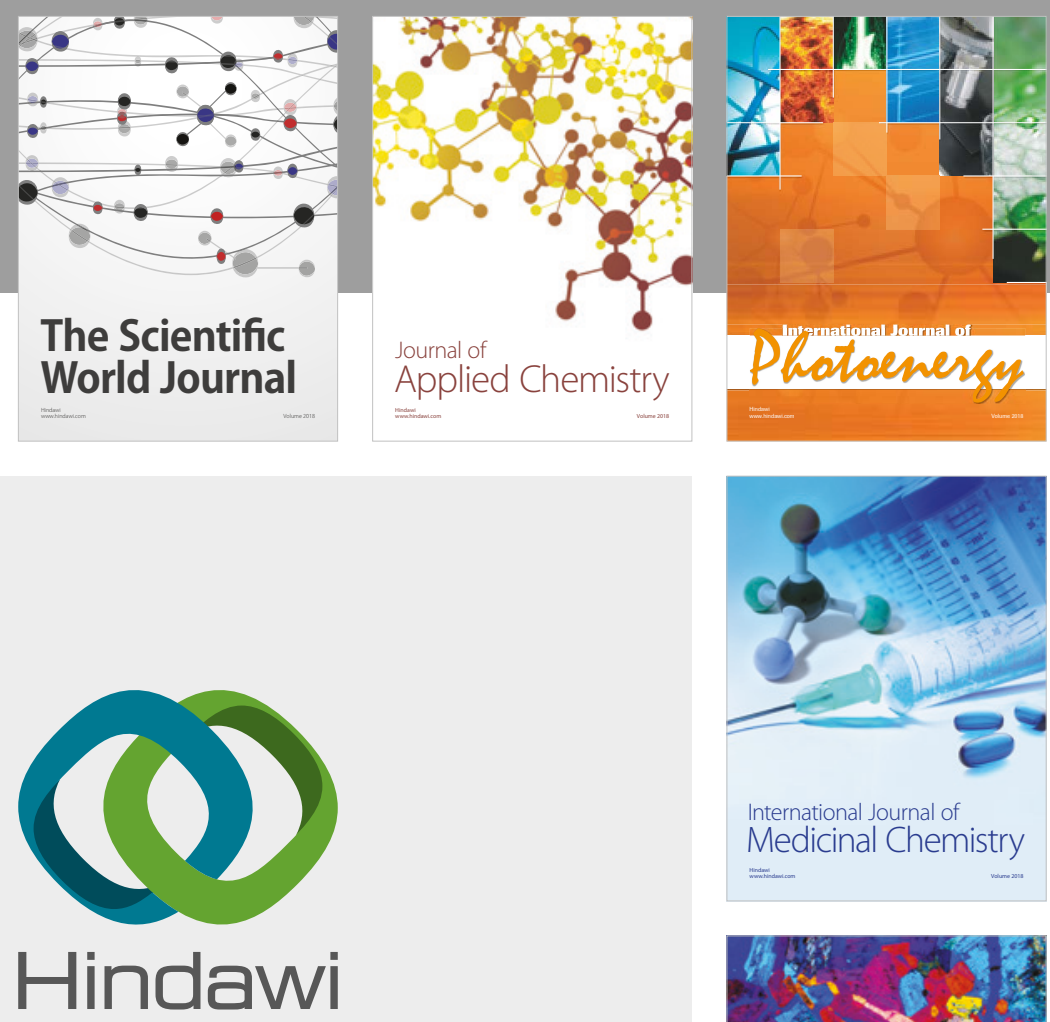

Submit your manuscripts at

www.hindawi.com
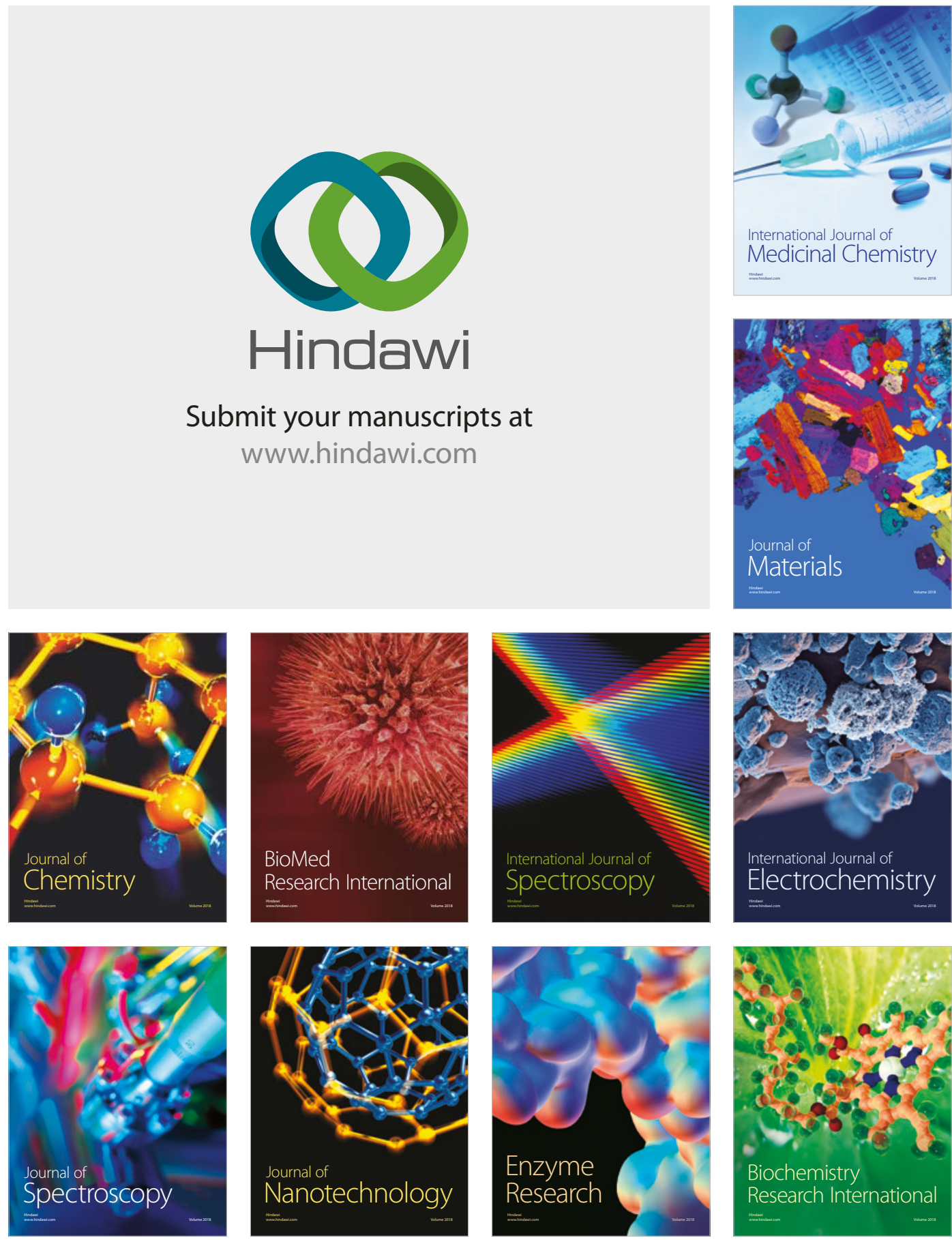
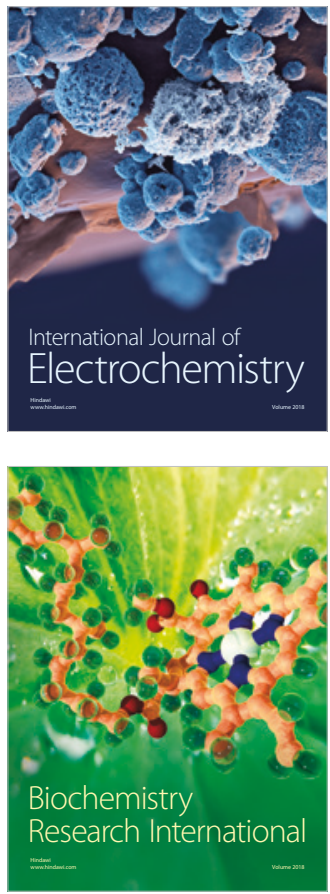